\title{
Shelf-slope exchanges associated with a steep submarine canyon off Calvi (Corsica, NW Mediterranean Sea): A modeling approach
}

\author{
N. Skliris, A. Goffart, J. H. Hecq, and S. Djenidi \\ Ecohydrodynamics, GeoHydrodynamics and Environment Research, University of Liège,, Liège, Belgium
}

\begin{abstract}
A three-dimensional, unsteady, nonlinear, high-resolution model is used to investigate the impact of the Calvi Canyon (NW Corsica) steep topography on the shelf-slope exchanges as well as on the circulation in the Calvi Bay in homogeneous winter and early spring conditions. A double $\sigma$ coordinate system is considered in order to represent adequately the high depth gradients within the canyon. The studied region is under the influence of the West Corsica Current flowing northeastward along the NW Corsican coast (right-bounded flow). Model results show that the circulation in the Calvi Bay is determined by flow modifications in the canyon area. The mean horizontal flow is deviated southwestward upstream of the canyon to form an anticyclonic gyre in the western part of the Calvi Bay. Within the canyon the circulation is cyclonic leading to an offshore flow downstream of the canyon. Around the canyon rim, the cross-shelf currents become important, indicating that this region acts as a transition zone of high exchange between nearshore and offshore areas. Furthermore, the canyon topography generates high downwelling (upwelling) and downsloping (upsloping) velocities responsible for an intense vertical transport of material in the area. Numerical runs are performed for typical prevailing wind conditions. The wind is responsible for a drastic increase of cross-shore transports between the bay and the canyon area (3-4 times larger than in the no-wind case). SW winds induce a further enhancement of cross-shelf exchanges, whereas the effect of N-NE winds is to reduce exchange at the shelf break apart from the canyon head where an intense offshore flow occurs. Within the canyon, high vertical velocities are shown to be associated with high cyclonic vorticity which is enhanced (reduced) by the N-NE (SW) wind event. A comparison between model results and measured distributions of nitrate and chlorophyll $a$ concentrations in the area shows the role played by this specific hydrodynamics as a strong constraint on the coastal pelagic ecosystem.
\end{abstract}

\section{Introduction}

Submarine canyons are prominent topographic features which modify the coastal circulation and induce high shelfslope exchanges of water and particles [Hickey et al., 1986; Durrieu de Madron, 1994; Monaco et al., 1999]. Owing to their topographic irregularity, canyons appear to be very difficult regions to make in situ measurements. In the past, only a few observational studies around canyons have been carried out and they were mainly focused on the along-canyon flow. Freeland and Denman [1982] observed a persistent upwelling region of dense water, characterized by a high nutrient content, on the coastal shelf near the Juan de Fuca Canyon (NE U.S. coast). They proposed that upwelling was associated to an upcanyon flow which was forced by the cross-shelf pressure gradient. Strong along-canyon axis motion has been also observed within canyons of the NE and NW U.S. coasts [e.g., Hickey et al., 1986; Hunkins, 1988; Noble and Butman, 1989]. More recently, a field study of the three-dimensional time-dependent circulation in relation to strong wind events

Copyright 2001 by the American Geophysical Union.

Paper number $2000 \mathrm{JC} 000534$.

0148-0227/01/2000JC534\$09.00 was carried out in the Astoria Canyon [Hickey, 1997]. Vertical velocity was highly correlated and in phase with alongshelf wind. Left-bounded flow (coast to the left, looking downstream) was shown to induce strong upwelling motion. A cyclonic circulation pattern was observed at deep depths, but only during conditions of weak incident flow.

A few observational studies on the NW Mediterranean coast have investigated the effects of submarine canyons on the shelf circulation. Remote sensing data indicated offshoreflowing filaments downstream of the Foix Canyon off the NE Spanish coast [La Violette et al., 1990]. On the same coast, field observations near Palamós [Masó and Tintoré, 1991] and Blanes [Rojas et al., 1995] canyons enlightened the presence of a cyclonic circulation within the canyons and an anticyclonic circulation in the downstream side of the canyons. Alvarez et al. [1996] analyzed the modifications induced by the short-timescale response of the slope current to the presence of Palamós Canyon. They demonstrated that the short-timescale variability was responsible for displacements of the jet interacting with the canyon and producing different regimes of shelf-slope exchange. Granata et al. [1999] reported important downwelling motion within the Blanes Canyon responsible for a high downward particle transport. A similar pattern was also observed in the Grand-Rhône Canyon on the Mediterranean coast of France [Durrieu de Madron, 
1994; Monaco et al., 1999]. In the NW Mediterranean coast canyons, the alongshore flow is generally right-bounded and induces favorable conditions for downwelling motion within the canyon, while in the NW U.S. case the alongshore flow is left-bounded and induces favorable conditions for upwelling.

Due to the complexity of the flow patterns, theoretical and numerical studies of the circulation near submarine canyons are still relatively scarce. Klinck [1988, 1989] used an analytical model to study the geostrophic adjustment of a stratified coastal current crossing an infinitely long canyon. It was shown that if the canyon width is less than half the internal radius of deformation, then the flow is generally along the canyon axis, generating vertical motions. For a very wide canyon, the current over the canyon is undisturbed by the bottom topography.

Allen [1996], with the help of a three-layer model, investigated both linear and nonlinear dynamics of a vertical-walled canyon cutting a uniform shelf. Simulations were performed only for left-bounded flows, considering different canyon's characteristics as well as stratification and wind conditions. Runs were also performed representing the geometry of Astoria and Tully Canyons (NW U.S. coast). Numerical results demonstrated that the effect of nonlinearity was to advect the flow pattern downstream as well as to enhance cyclonic vorticity within the canyon, in agreement with field observations over Astoria Canyon. However, the agreement for Tully Canyon was much poorer and the discrepancy of the solution was attributed to the complexity of the topography.

Klinck [1996] implemented a nonlinear semispectral primitive equation multilayer model to look at the response of a canyon to both left- and right-bounded incident flows, under weakly and strongly stratified conditions. The bottom topography was represented by an uniform shelf that was cut in the middle of the alongshore distance by a canyon of triangular shape. Numerical results indicated that the most important factor controlling shelf-slope exchanges was the direction of the along-shelf flow, where the left-bounded flow (upwelling favorable case) induced much stronger exchange at the shelf break. The effect of stratification was to limit the vertical extent of the topography so that the incident flow was only weakly affected by the presence of the canyon under strongly stratified conditions. Vertical viscosity and wind stress were ignored in the various simulations and, consequently, the bottom and surface Ekman layers dynamics were not investigated.

So far, mainly process studies with simple geometry/topography of shelf and canyon domains were considered in order to assess the adjustment occurring between the baroclinic flow and the canyon topography. More recently, Ardhuin et al. [1999] studied the circulation in the Blanes Canyon area using a free-surface three-dimensional primitive equation model, with real canyon and shelf topography. Results indicated the presence of a geostrophic anticyclonic circulation in the intermediate layers within the canyon, while near the surface the flow was undisturbed by the canyon topography. The effect of wind forcing on the flow pattern was to generate significant vertical and cross-shore motions steered by the topographic slope.

In all of these modeling studies, canyon interaction with irregular nearshore topography, such as a bay configuration, where nonlinear processes, bottom and surface Ekman layers dynamics become very important, was not considered. In the present study, a three-dimensional nonlinear primitive equa- tion model of high horizontal and vertical resolution is used, to represent a nonlinear viscous flow over realistic canyon and nearshore topography. The site under interest is the Calvi area (Figure 1) which is located on the NW Corsica coast (NW Mediterranean Sea).

\section{Regional Circulation in the Calvi Area}

The Calvi coastal area is characterized by a small-scale, very narrow $(\sim 3 \mathrm{~km}$ mean width), deep ( $\sim 600 \mathrm{~m}$ mean depth), and steep-sided (up to $40^{\circ}$ bottom slope) canyon (Figure 1). It intrudes approximately $6 \mathrm{~km}$ onto an irregular and narrow shelf. The canyon head, located in front of the Calvi Bay, bisects the shelf into two parts. The large-scale dominant element of the hydrodynamics of the Ligurian Provençal Basin (NW Mediterranean) is a well-defined cyclonic circulation, where a quasi-permanent slope geostrophic current is present [Millot, 1991]. Off the NW Corsican coast the socalled West Corsican Current (WCC) is directed northeastward and exhibits a seasonal variability, with the lowest values in late summer and autumn, progressively increasing in intensity to a maximum in early summer [Astraldi and Gasparini, 1992]. The current offshore of the Calvi Bay is in quasi-geostrophic balance, following the isobaths, and thus reducing cross-shelf exchanges. However, the Calvi Canyon being across the path of the current, induces a new dynamic balance, which is nongeostrophic. Nonlinear processes become important in the vicinity of a narrow canyon. An indicator of nonlinearity within the canyon could be the Rossby number $\left(R_{o}=U / f L\right)$, representing the relative importance of momentum advection, where $U$ is the incident current velocity in the canyon, $f$ the Coriolis parameter and $L$ the horizontal length scale that can be taken equal to the half width of the canyon. For the Calvi Canyon, where $U \sim 0.1 \mathrm{~m} \mathrm{~s}^{-1}$ and $L \sim 1.5$ $\mathrm{km}, R_{o}$ is $\sim 0.7$, indicating that advection of momentum plays an important role on the flow pattern. Bottom friction can induce a further enhancement of the ageostrophic transport. In addition, strong wind events often occurring in this region, namely, the Libeccio (blowing from the southwest), and the Tramontane (blowing from the north-northeast) are responsible for complex flow patterns. For such a complicated flow structure a numerical modeling approach is necessary in order to estimate the relative importance of the various non-linear processes controlling the fluxes of water and particles in the area.

In previous studies the circulation in the Calvi Bay was investigated on the basis of field observations. Long-term measurements of subsurface currents (mean current velocity every $10 \mathrm{~min}$ at $10 \mathrm{~m}$ depth) and of meteorological parameters (mean wind speed and direction every $10 \mathrm{~min}$ at $6 \mathrm{~m}$ height above the sea surface) were made in the vicinity of Calvi during and after the Medalpex experiment (1981-1983) [Djenidi, 1985; Djenidi et al., 1987]. Figure 2a shows some examples of current measurements in key locations, presented under the form of progressive vector diagrams drawn for several weeks periods. Observations highlighted a mean anticyclonic circulation in the western part of the bay and a slightly weaker cyclonic circulation in the eastern part of the bay (Figure 2b). An offshore flow downstream of the canyon head was also reported. Transient upwelling structures accompanied with flow reversals were observed during strong wind events (Figures $2 \mathrm{c}$ and $2 \mathrm{~d}$ ). However, the flow variability was not always clearly related to the local meteorological 
(a)
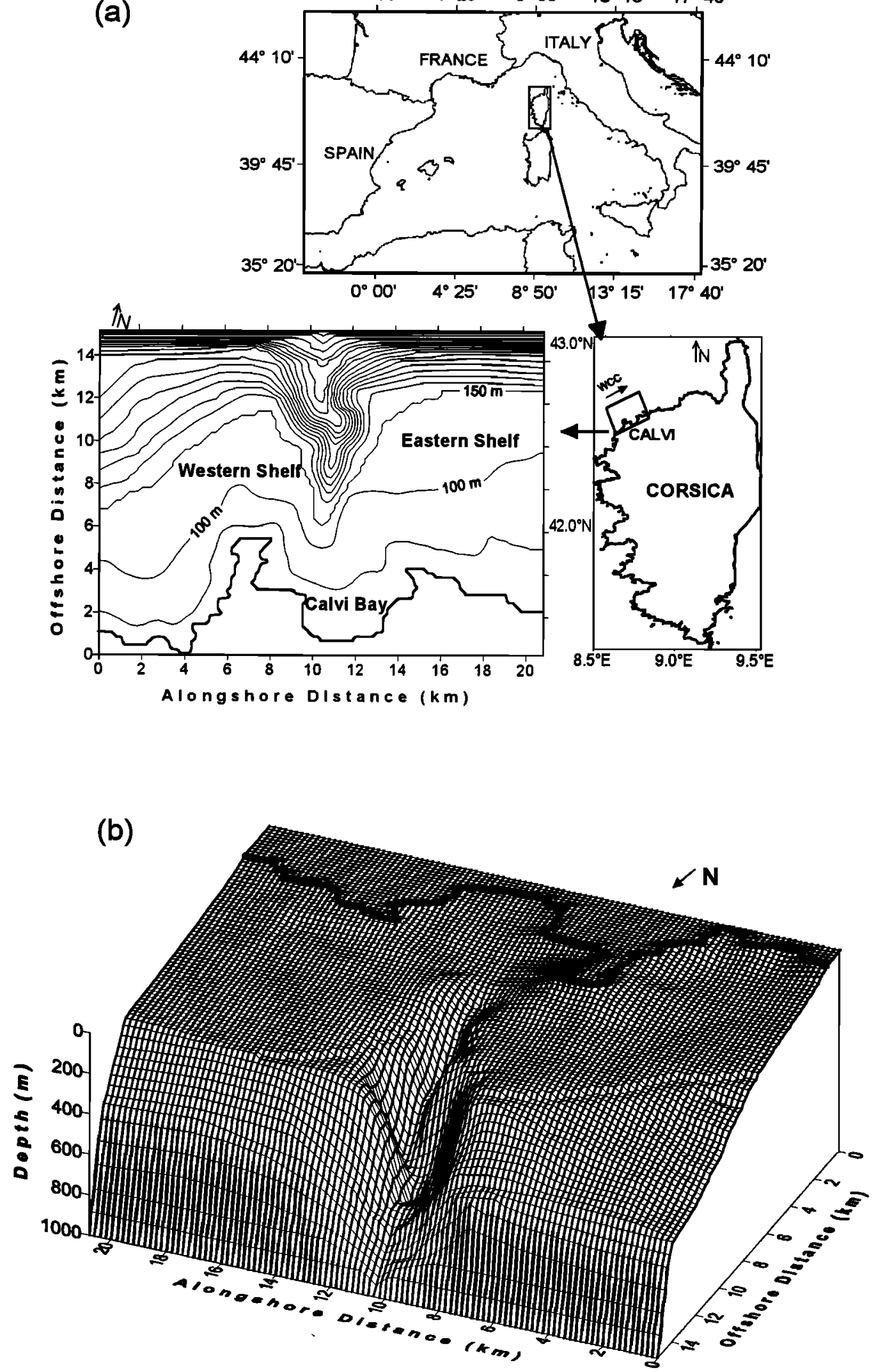

Figure 1. (a) Bathymetry and location of the Calvi Canyon area (model domain) on the NW Corsican coast. Corsica's location in the NW Mediterranean and the direction of the West Corsica Current (WCC) are indicated. The contour interval for the isobaths is $50 \mathrm{~m}$. (b) Bottom topography of the model domain. 
events, and the hypothesis of effects of Ligurian Provençal front instabilities through the canyon region was suggested.

Norro [1995], based on current, wind and temperature measurements, demonstrated the existence of strong coastal upwelling motion in the eastern part of the bay in relation to local strong N-NE wind events. A mean anticyclonic circulation within the whole bay was proposed. However, it was suggested that the flow pattern was not always associated with local meteorological conditions but was rather imposed by the offshore circulation.

In these studies the influence of the canyon topography was not really examined, so that the objective of this work is to investigate this influence on the shelf-slope exchanges as well as on the circulation in the Calvi Bay, by means of the GeoHydrodynamics and Environment Research (GHER) laboratory of the University of Liège three-dimensional model. Special attention will also be paid on the additional effects of the meteorological forcing on the flow patterns.

\section{Numerical Model}

The study is based on the GHER three-dimensional baroclinic nonlinear primitive equation model using a $k$-l turbulent closure [Nihoul and Djenidi, 1987; Nihoul et al., 1989]. The model is adapted to the spectral window of mesoscale processes and assumes the Boussinesq and the quasi-hydrostatic equilibrium approximations. The equations of the prognostic variables (sea surface elevation, the three components of

(a)
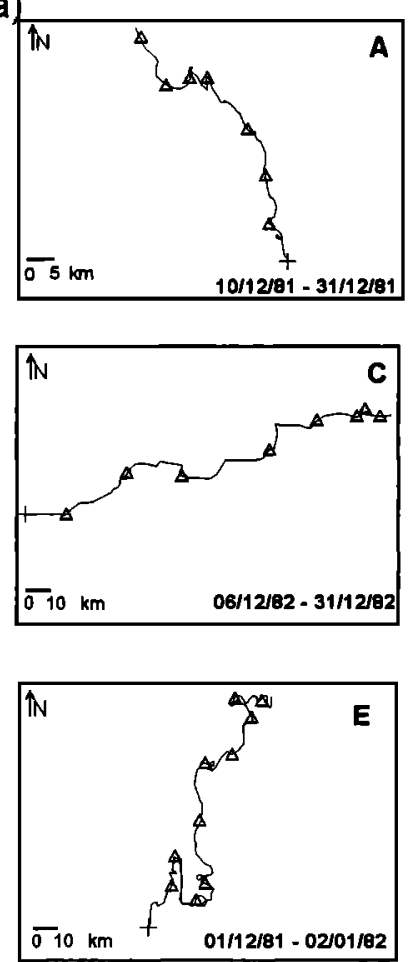
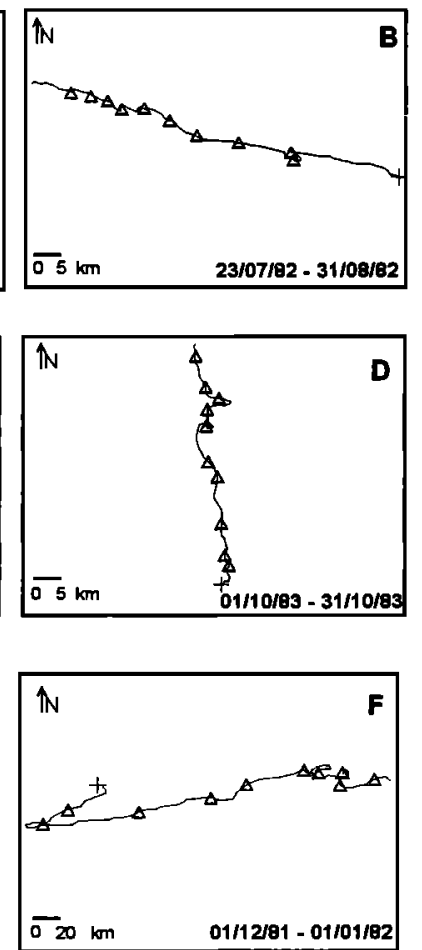

velocity, temperature, salinity, and turbulent kinetic energy) are solved numerically using the so-called sigma coordinates [e.g., Freeman et al., 1972; Blumberg and Mellor, 1987; Deleersnijder, 1989]. The basic equations are formulated as follows:

$$
\frac{\partial \zeta}{\partial t}+\tilde{\nabla}_{h} \cdot(H \mathbf{u})+\frac{\partial}{\partial \sigma}(H w)=0
$$

$$
\begin{aligned}
& \frac{\partial(H \mathbf{u})}{\partial t}+\tilde{\nabla}_{h} \cdot(H \mathbf{u u})+\frac{\partial}{\partial \sigma}(w H \mathbf{u})+f \mathbf{e}_{3} \times H \mathbf{u} \\
& =H\left\{\tilde{\nabla}_{h}(g \zeta)-\tilde{\nabla}_{h} \int_{\sigma}^{1} H b d \sigma+\left[(1-\sigma) \tilde{\nabla}_{h} h-\sigma \tilde{\nabla}_{h} \zeta\right] H b\right\}
\end{aligned}
$$
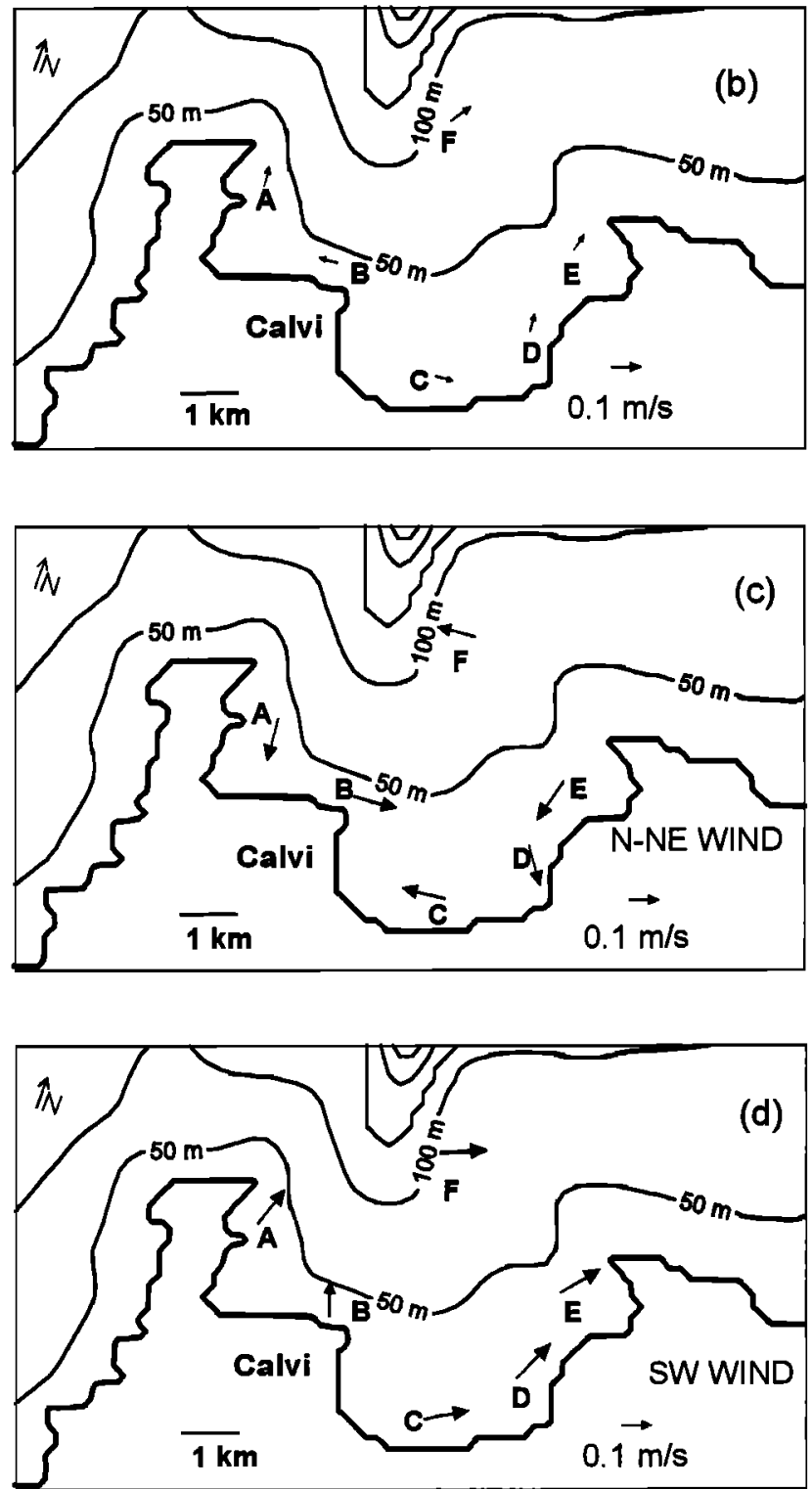

Figure 2. Subsurface $(-10 \mathrm{~m})$ current measurements in the Calvi Bay. A, B, C, D, E and F represent the locations of the moorings. (a) Selected typical progressive vector diagrams, where the pluses indicate the beginning of measurements, and the distance between two successive triangles corresponds to a 3 days period. The total period of measurements is also depicted. (b) Mean circulation pattern during low wind conditions (wind intensity lower than $4 \mathrm{~m} \mathrm{~s}^{-1}$ ). (c) Mean circulation pattern during SW wind events (wind intensity larger than 7 $\mathrm{m} \mathrm{s}^{-1}$ during at least 12 hours). (d) Mean circulation pattern during NE wind events (wind intensity larger than $7 \mathrm{~m} \mathrm{~s}^{-1}$ during at least 12 hours). The contour interval for the isobaths is $50 \mathrm{~m}$. 


$$
\begin{aligned}
& +\frac{\partial}{\partial \sigma}\left[\frac{\tilde{v}}{H^{2}} \frac{\partial(H \mathbf{u})}{\partial \sigma}\right]+\tilde{\nabla}_{h}\left[K_{h} \tilde{\nabla}_{h}(H \mathbf{u})\right] \\
& \frac{\partial(H T)}{\partial t}+\tilde{\nabla}_{h} \cdot(H \mathbf{u} T)+\frac{\partial}{\partial \sigma}(w H T)=\frac{\partial}{\partial \sigma}\left[\frac{\tilde{\lambda}}{H^{2}} \frac{\partial(H T)}{\partial \sigma}\right] \\
& +\tilde{\nabla}_{h} \cdot\left[K_{h} \tilde{\nabla}_{h}(H T)\right] \\
& \frac{\partial(H S)}{\partial t}+\tilde{\nabla}_{h} \cdot(H \mathbf{u} S)+\frac{\partial}{\partial \sigma}(w H S)=\frac{\partial}{\partial \sigma}\left[\frac{\tilde{\lambda}}{H^{2}} \frac{\partial(H S)}{\partial \sigma}\right] \\
& \left.+\tilde{\nabla}_{h} \cdot K_{h} \tilde{\nabla}_{h}(H S)\right] \\
& b(T, S)=-g \frac{\rho-\rho_{o}}{\rho_{o}}, \\
& \frac{\partial(H k)}{\partial t}+\tilde{\nabla}_{h} \cdot(H \mathbf{u} k)+\frac{\partial}{\partial \sigma}(w H k)=\frac{\tilde{\nu}}{H}\left\|\frac{\partial \mathbf{u}}{\partial \sigma}\right\|^{2}\left(1-R_{f}\right) \\
& -H \frac{k^{2}}{16 \tilde{v}}+\frac{\partial}{\partial \sigma}\left[\frac{\tilde{v}}{H^{2}} \frac{\partial(H k)}{\partial \sigma}\right]+\tilde{\nabla}_{h} \cdot\left[K_{h} \tilde{\nabla}_{h}(H k)\right] \\
& R_{f}=H \frac{\tilde{\lambda}\left\|\frac{\partial b}{\partial \sigma}\right\|}{\tilde{v}\left\|\frac{\partial \mathbf{u}}{\partial \sigma}\right\|^{2}}, \\
& \tilde{\boldsymbol{v}}=0.5 \kappa \sigma H(1-0.75 \sigma)\left(1-R_{f}\right) \sqrt{k} \text {, } \\
& \tilde{\lambda}=\tilde{v} 1.1 \sqrt{1-R_{f}}, \\
& \sigma=\frac{x_{3}+h}{H}, \sigma \in[0,1] \text {, } \\
& H=h+\zeta \text {, } \\
& \tilde{\nabla}_{h}=\nabla_{h}-\nabla_{h}(\sigma) \frac{\partial}{\partial \sigma},
\end{aligned}
$$

where $\mathbf{u}(u, v)$ is the horizontal velocity vector, $w$ is the vertical velocity in the $\sigma$ coordinate system, $e_{3}$ is the unit vertical vector pointed upwards with its origin at the unperturbed free surface, $\zeta$ is the sea surface elevation, $h$ is the reference depth, $f$ is the Coriolis parameter, $g$ is the acceleration of gravity, $b$ is the buoyancy, $T$ is the temperature, $S$ is the salinity, $k$ is the turbulent kinetic energy, $\rho$ is the local density of the seawater, $\rho_{o}$ is a reference Boussinesq density, $\tilde{v}$ is the vertical eddy viscosity, $\widetilde{\lambda}$ is the vertical eddy diffusivity, $\kappa$ is the von Karman constant, $K_{h}$ is the horizontal diffusion coefficient, and $R_{f}$ is the flux Richardson number.

The real "physical space" vertical velocity $v_{3}$ is not explicitly involved in the transformed equations, but it may be evaluated in the posttreatment of the model results. According to Deleersnijder [1989], $v_{3}$ may be split into two contributions:

$$
\begin{gathered}
v_{3}=w_{u w}+w_{u s}, \\
w_{u w}=H w, \\
w_{u s}=\sigma\left(\frac{\partial \zeta}{\partial t}+\mathbf{u} \nabla_{h} H\right)+\mathbf{u} \nabla_{h} h,
\end{gathered}
$$

where $w_{u w}$ and $w_{u s}$ are the upwelling and upsloping velocities, respectively. Variable $w_{u w}$ is the vertical velocity cutting across iso- $\sigma$ surfaces, associated with proper upwelling or downwelling motions. Variable $w_{u s}$ may be seen as the vertical velocity adapted to the slopes of the sea surface and the bottom. Hence a particle moving with upsloping velocity does not cross the iso- $\sigma$ surfaces and thus remains at the same relative height in the water column. The decomposition of vertical velocity in the $\sigma$ coordinate system provides a better understanding of vertical motions, separating that due to basin topography (upsloping-downsloping) from that due to Ekman circulation (upwelling-downwelling) [Deleersnijder, 1989; Beckers, 1991].

The classical $\sigma$ coordinate system presents some other practical advantages: since $\sigma$ coordinates fit the bottom and surface topography, in $\sigma$ space, the water column has the same height everywhere and surface and bottom boundary conditions reduce to zero vertical velocity. Moreover, there is no waste of computer memory since all grid points on the vertical are in the water column. However, in regions of deep and highly varying topography, such as canyons, the use of a single $\sigma$ coordinate system has a major drawback. Over steep topography $\sigma$ coordinates become very inclined to the horizontal. Although iso- $\sigma$ surfaces correspond to preferential directions of motion near the surface and bottom boundaries, this is not the case for the interior of the domain, where the flow generally follows horizontal or isopycnal surfaces. Hence subgrid scale diffusion or advective fluxes which would be normally in an horizontal plane become inclined to the grid in $\sigma$ space, inducing, for example, the destruction of thermoclines or nitraclines. To avoid this inconvenience a double $\sigma$ transformation is proposed [Beckers, 1991; Deleersnijder and Beckers, 1992]. The domain is divided in two superposed interconnected layers, the upper layer's depth following the shelf bathymetry on the shelf and remaining at maximum shelf's depth in the deep sea (Figure 3). In each layer the classical $\sigma$ transformation is applied:

$$
\begin{gathered}
\sigma_{1}=\frac{x_{3}+\min \left(h, h_{L}\right)}{\min \left(h, h_{L}\right)+\zeta}, \\
\sigma_{2}=\frac{x_{3}+h}{h-h_{L}},
\end{gathered}
$$

where $\sigma_{1}, \sigma_{2}$ denote the vertical $\sigma$ coordinates in the upper and lower layer, respectively, and $h_{L}$ is the depth of the horizontal plane $\left(x_{3}=-h_{L}\right)$ separating the two layers. Here $h_{L}$ is taken equal to $150 \mathrm{~m}$ assuming that the $150 \mathrm{~m}$ isobath presents the best fit to the shelf edge contour line. Hence the shelf domain $\left(h<h_{L}\right)$ involves only the upper layer. At the shelf edge the shelf domain is separated from the deep one by a vertical wall. The double- $\sigma$ transformation allows a more accurate representation of mixed layer's processes in the deep canyon region. Indeed, in that case $\left(h>h_{L}\right)$ the bottom of the upper layer is fixed at $x_{3}=-h_{L}$, so that the iso- $\sigma$ surfaces are quasi-horizontal planes in the real space. The system of governing equations described above is then applied separately in the two layers. The connection between upper and lower layer is ensured by expressing the continuity of vertical advection and diffusion fluxes at the interface $x_{3}=-h_{L}$.

The numerical model uses a mode-splitting technique based on the simultaneous resolution of a depth-integrated model to compute the sea surface elevation. The spatial discretisation uses a finite volume technique [Peyret and Taylor, 


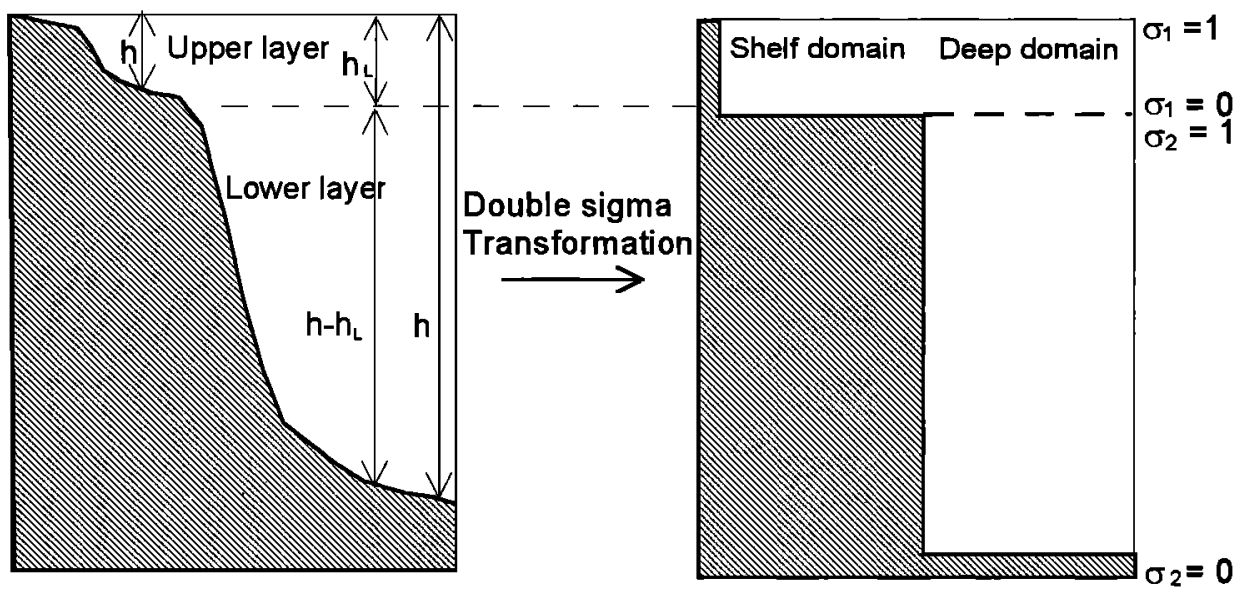

Figure 3. Schematic representation of real and transformed domains in the double sigma coordinate system.

1983] on an Arakawa $C$ grid. Vertical advection and diffusion are treated with an implicit Crank-Nicolson time [Crank and Nicolson, 1947] centered space scheme which combines second-order time and space accuracy with unconditional stability. Horizontal advection is represented by a hybrid scheme [James, 1996] varying between the Lax-Wendroff secondorder scheme and the upwind first-order scheme, according to stability requirements. The computational domain $(21 \mathrm{~km} \times$ $15.2 \mathrm{~km})$ is discretized with high horizontal resolution $(200 \mathrm{~m}$ $\times 200 \mathrm{~m}$ ) in order to represent adequately the bathymetry gradients in the deep canyon area. The vertical discretisation uses $10 \sigma$ levels for the upper layer $(h \leq 150 \mathrm{~m})$ and $10 \sigma$ levels for the deep layer $(h>150 \mathrm{~m})$. The time step is $1.2 \mathrm{~s}$ for the barotropic mode and $12 \mathrm{~s}$ for the baroclinic mode.

The classical bulk formulas are used to determine the turbulent fluxes at the air-sea interface. The surface boundary

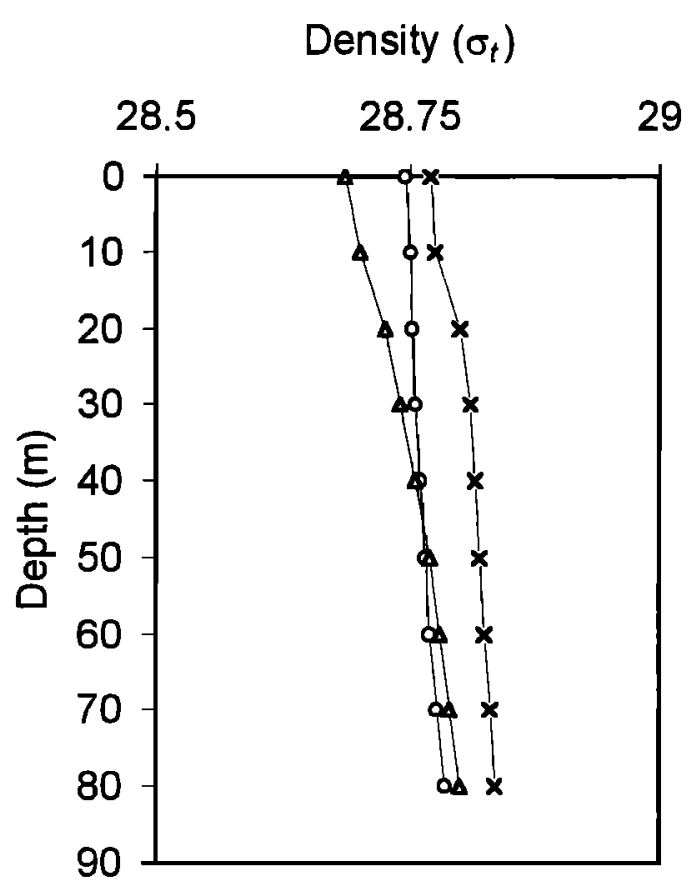

Figure 4. Density profiles (in $\sigma_{t}$ units) on the western continental shelf off Calvi. Measurements were made on February 20, 1984 (circles), March 10, 1983 (crosses), and April 3, 1985 (triangles). conditions for $k$ and $\mathbf{u}$ are obtained by expressing the continuity of the momentum and turbulent kinetic energy fluxes [e.g., Nihoul, 1984]:

$$
\begin{gathered}
\left.\tilde{v} \frac{\partial \mathbf{u}}{\partial x_{3}}\right|_{\text {surf }}=\frac{\rho_{a}}{\rho_{w}} C_{V}\left\|\mathbf{V}_{10}\right\| \mathbf{V}_{10}, \\
\tilde{v} \frac{\partial k}{\left.\partial x_{3}\right|_{\text {surf }}}=\frac{\rho_{a}}{\rho_{w}} C_{K}\left\|\mathbf{V}_{10}\right\|^{3},
\end{gathered}
$$

where $\rho_{a}$ is the specific mass of air at sea level, $\rho_{w}$ is the specific mass of seawater, $C_{V}$ and $C_{K}$ are appropriate bulk exchange coefficients, and $V_{10}$ is the wind speed measured at $10 \mathrm{~m}$ height above the sea surface.

We assume a logarithmic bottom layer. The bottom stress $\tau_{b}$ is parameterized by [e.g., Blumberg and Mellor, 1987]

$$
\tau_{b}=\left.\tilde{v} \frac{\partial \mathbf{u}}{\partial z}\right|_{\text {bottom }}=\left(\frac{0.4}{\ln \frac{z(1)}{z_{o}}}\right)^{2}\|\mathbf{u}(1)\| \mathbf{u}(1),
$$

where $z(1)$ is the height of the center of the first grid cell where the velocity $\mathbf{u}(\mathbf{1})$ is calculated and $z_{o}$ is the roughness length $(=0.003)$.

The bottom boundary conditions for $k$ have been derived, assuming that production balances dissipation of $k$ with neutral stratification:

$$
k=4 \tilde{v}\left\|\frac{\partial \mathbf{u}}{\partial z}\right\| .
$$

Weak horizontal diffusion of momentum is introduced ( 5 $\mathrm{m}^{2} \mathrm{~s}^{-1}$ ) to filter out small-scale computation noise, mostly arising because of the current interaction with the steep topography of the domain.

The open boundary conditions are determined on the basis of field observations of the West Corsica Current off Calvi [Astraldi and Gasparini, 1992]. At the outer northern boundary, defined at the $1000 \mathrm{~m}$ isobath, the cross-shore depthaveraged flow is set to zero. This is meant to reproduce an along-isobath geostrophic flow which perturbs in the least way possible the internal solution. An uniformly increasing current velocity distribution is imposed for the depth-averaged flow at the western boundary with a maximum value of $10 \mathrm{~cm}$ 
(a)
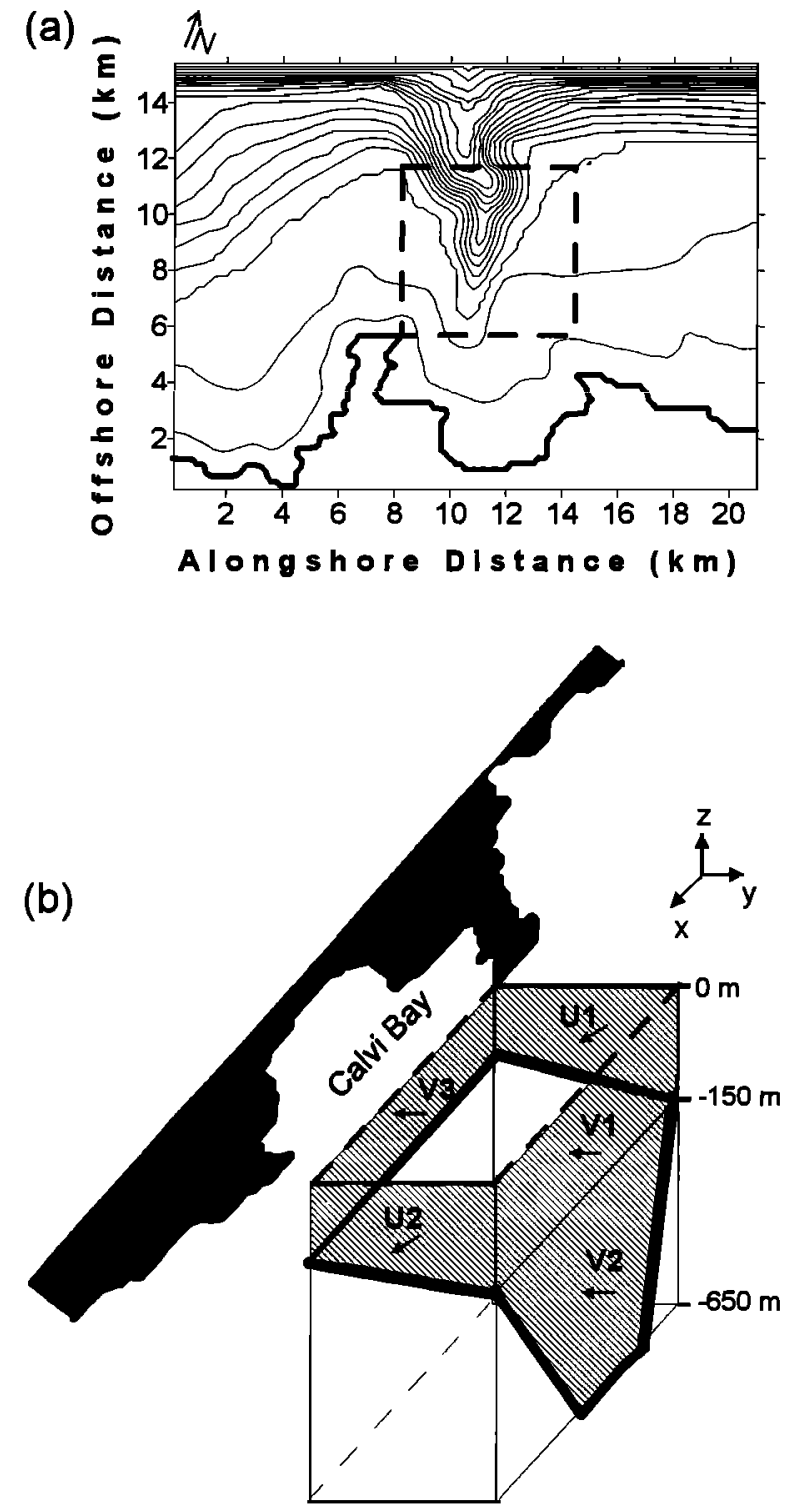

Figure 5. Schematic representation of the closed box where volume transports are computed. (a) Representation of the horizontal upper side of the box at the sea surface (thick dashed lines). (b) Orientation of the box relative to the Calvi Bay location and schematic representation of the volume transports through the vertical sides of the box. Alongshore transports $U$ are calculating along the cross-shore vertical sides of the box, whereas cross-shore transports $V$ are calculated over the alongshore vertical sides. The thick solid lines represent the bottom slope in each vertical side of the box, while the thick dashed lines represent the upper side of the box at the sea surface as indicated in Figure 5a.

$\mathrm{s}^{-1}$ in the outer grid cell. Constant Dirichlet conditions are considered for the coastline and the outer boundary. A radiation condition is imposed at the eastern open boundary, allowing disturbances originating in the interior of the domain to leave it without disturbing the internal solution [Roed and Cooper, 1987]. No boundary condition is required for the sea surface elevation, which is computed from the continuity equation. Concerning the 3-D flow, constant Dirichlet conditions are considered for the solid walls, whereas the vertical structure of currents at the open sea boundaries is allowed to develop from the internal solution. Zero normal derivative of the deviation from the vertically averaged horizontal velocity is assumed. At the western boundary the turbulent kinetic energy vertical profile is calculated by assuming that production balances dissipation of energy, whereas a radiation condition is imposed at the eastern boundary.

\section{Results and Discussion}

With the aim of appraising the canyon and wind forcing effects on flow patterns, a homogeneous density field is assumed, which is representative of that observed from mid December to late March. Figure 4 shows typical density profiles on the western continental shelf off Calvi at the end of winter and in early spring. The vertical density gradient remains at low levels until the beginning of April. Typical den sity profiles for the open sea in the Liguro-Provençal basin (NW Mediterranean) during that period also show rather homogenous density conditions in the deeper layers [Goffart et al., 1995]. The mean vertical density gradient in late February is of the order of $3 \times 10^{-4}\left(\mathrm{~kg} \mathrm{~m}^{-3} \mathrm{~m}^{-1}\right)$. Preliminary simulations performed for a nonstratified case and for this weakly stratified case did not show any significant difference with respect to the horizontal and vertical current velocity fields. This weakly stratified period includes the phytoplankton bloom, which generally occurs in the Calvi Bay from mid February to mid March [Goffart et al., 1995]. At the initial time the domain is assumed to be at rest. The model has been first tested in negligible wind conditions in order to simulate the topography induced circulation. The simulated flow is generated by the West Corsican Current imposed on the western boundary and is strongly influenced by the bathymetric variations. The numerical runs are performed until reaching a quasi-steady state of the flow. The flow pattern for the nowind case is established by model day 8 . Then simulations are performed to evaluate the additional effect of typical wind events on the dynamics. For each case of southwesterly and north-northeasterly prevailing winds a constant velocity of 10 $\mathrm{m} \mathrm{s}^{-1}$ and a 24 hours duration are used for the simulations, these values being representative of typical atmospheric conditions in the region [Djenidi, 1985; Norro, 1995]. At the initial time, a steady state flow, obtained from the no-wind simulation, is imposed.

For the three model cases the results are represented here by the horizontal and vertical current velocity fields. The depth mean, surface (grid cell nearest to the sea surface), and bottom (grid cell nearest to the bottom) layer velocities values are displayed for the horizontal current. Vectors only for the "odd" grid points are depicted. For the vertical current the depth mean value is displayed. In order to estimate the crossshelf exchanges, the cross-shelf and the along-shelf volume transports above the shelf break (fixed at $150 \mathrm{~m}$ depth) are derived for the various runs, assuming that the $150 \mathrm{~m}$ isobath represents the slope of the shelf.

In order to evaluate the alongshore and cross-shore fluxes within the canyon area as well as the water exchange between the canyon and the Calvi Bay volume transports are computed at the sides of a closed box (Figure 5). The alongshore and cross-shore dimensions of the box are $6 \mathrm{~km} \times 6 \mathrm{~km}$. The southern alongshore vertical side of the box is located between the canyon head and the Calvi Bay, while the northern one intersects the canyon and shrinks to $650 \mathrm{~m}$ depth at the bottom. The northern side is divided into two planes corre- 

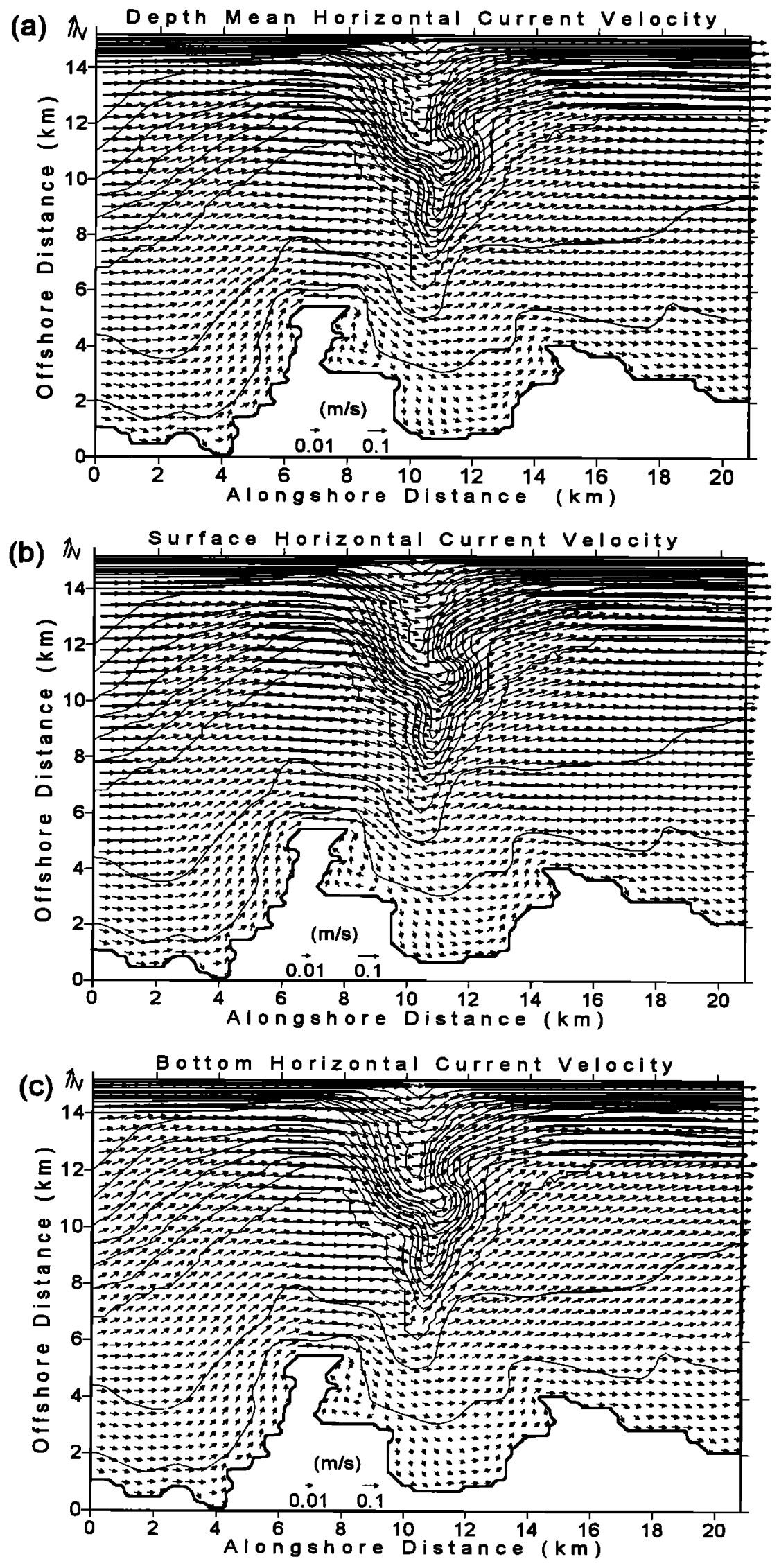

Figure 6. Horizontal current velocities $\left(\mathrm{m} \mathrm{s}^{-1}\right)$ for the no-wind case. Isobaths with a contour interval of $50 \mathrm{~m}$ are also depicted. (a) Depth mean velocity. (b) Near surface velocity (top grid cell). (c) Near bottom velocity (bottom grid cell). 
sponding to the upper $150-\mathrm{m}$ layer and the lower deep layer of the computational domain. Cross-shore volume transports $V_{1}$ and $V_{2}$ are calculated for the northern alongshore side while the cross-shore volume transport $V_{3}$ is calculated for the southern one. Alongshore volume transports $U_{1}$ and $U_{2}$ are calculated for the western and eastern cross-shore sides of the box, respectively. The vertical transport across the $150 \mathrm{~m}$ horizontal plane $W$ within the box is also calculated. For each vertical alongshore and cross-shore plane, and, for the horizontal plane, the total net transport as well as the total positive and negative transports are computed. Transports are counted positively when directed offshore, eastward or upward and negatively when directed onshore, westward or downward.

For the model validation, numerical results may be verified for the surface currents within the Calvi Bay and downstream of the Canyon head (see Figure 2). However, there are no data available within the canyon.

\subsection{Simulation in the Negligible Wind Case}

Figure 6a shows the model solution for the depth mean current in the no-wind case. The mean horizontal flow is more or less in geostrophic balance and tends to follow the bathymetry of the domain. However, upstream of the canyon the flow is deflected southward while the increase of the depth gradient around the canyon rim induces an increase of current velocity. As a consequence, the ageostrophic component of the current is enhanced, causing a meandering of the flow. The simulated flow is consistent with that expected from classical arguments for the conservation of potential vorticity. Upstream of the canyon a part of the flow is deviated onshore, in shallow depths, leading to the increase of negative relative vorticity. Anticyclonic circulation is evidenced in the westem shelf as well as in the western part of the Calvi Bay, where an anticyclonic gyre takes place. A few observational studies of current/canyon interaction in the NW Mediterranean evolving regular coastlines [e.g., Rojas et al., 1995; Granata et al., 1999] enlighten the existence of anticyclonic circulation upstream of the canyon. On the other hand, potential flow theory predicts an acceleration of the flow and generation of vorticity around headlands [e.g., Robinson, 1981], features which are supported by some field evidence [e.g., Geyer and Signell, 1990]. The increased current velocity and the shallower depth near the headland result in greater depth average friction force inshore. For a right-bounded flow this mechanism creates anticyclonic vorticity downstream of the headland. In addition, separation of the flow from the coastline as it flows around the headland may occur [e.g., Robinson, 1983]. Our model results show clearly the expected flow acceleration around the headland in the western corner of the Calvi Bay. Therefore we conclude that both canyon and headland topographic features contribute to the generation of the anticyclonic gyre in the western part of the bay.

Over the canyon the flow acquires positive potential vorticity due to the depth increase and a cyclonic circulation is formed, producing an offshore transport downstream of the canyon. In the eastern part of the bay the flow also obtains cyclonic vorticity leading to an offshore transport. The simulated circulation pattern in the Calvi Bay and downstream of the canyon head is in agreement with the field observations (see Figure 2b). As canyon water moves onto the eastern shelf, the flow requires again negative relative vorticity due to the depth decrease.
Over the canyon the flow pattern (Figure 6a) is consistent with that observed in canyon regions of the NW Mediterranean [La Violette et al., 1990; Masó and Tintoré, 1991; Durrieu de Madron, 1994]. The canyon acts as a barrier deflecting the flow southward on the upstream side, and then, deflecting the flow northward on the downstream side. The structure and the dynamics of this cyclonic circulation within the canyon are also consistent with the model of Klinck [1996] simulating a right-bounded coastal flow (coast to the right of the current) over a canyon. As the flow at the shelf break is deflected toward the coast, it is decelerated by the geostrophic pressure gradient, which is offshore in this case. As a result, the Coriolis acceleration is reduced, allowing the flow to move offshore. Passing the canyon axis, the flow is then accelerated by the pressure gradient, inducing the increase of Coriolis acceleration, so that the water is pushed offshore until roughly reaching its original alongshore isobath (the isobath that the water mass was following before encountering the canyon).

Model results show a barotropic adjustment over the canyon where the flow obtains cyclonic vorticity, but no closed eddy structure forms, as the one predicted by Ardhuin et al. [1999] for the Blanes Canyon, also located in the NW Mediterranean. Settings of that model are similar to ours (rightbounded flow, forcing restricted to the upstream boundary) except for the stratification conditions which, unlike our model, involve high horizontal density gradients and thus imply a strong baroclinic flow. Their results show strong current shear in the horizontal and vertical, allowing crossisobath flows over the canyon and eddies to form within the canyon. Unlike Blanes canyon area, the density front, developing in spring, is located much more offshore of the Calvi Canyon ( $30 \mathrm{~km})$ [Goffart et al., 1995] so that horizontal stratification is weak in our study domain. Runs performed by Ardhuin et al. [1999] with weakly stratified conditions also show a barotropic adjustment over the canyon with the flow following the isobaths as in our model results.

Surface and bottom layer currents (Figures $6 \mathrm{~b}$ and 6c) present a similar structure to that of the depth mean flow since there is no significant external forcing driving vertical gradients of the horizontal current field. However, weak vertical motion (Figure 7a) is evident near the coast due to the Ekman bottom layer friction, which causes the veering of the bottom current to the left of the mean current. Moreover, in the bottom of the canyon, the circulation is weaker, especially near the topographic slope, but the cyclonic vorticity of the flow is more pronounced due to bottom friction and current deflection by the solid wall.

Model results demonstrate that the steep canyon topography is responsible for the enhancement of the vertical flow. While upstream of the canyon, flow intensity is increased to reach maximum current velocities around the rim, over the canyon surface velocities are reduced, with minimum current velocities on the central axis of the canyon. The surface convergence of the horizontal flow can be explained by vortex stretching. As water falls into the deep canyon area, water layers are stretched downward, producing strong vertical motion near the surface. Downwelling (maximum depth mean speed of $-7.8 \times 10^{-3} \mathrm{~m} \mathrm{~s}^{-1}$ ) is observed on the western side of the canyon, whereas upwelling of lower intensity (maximum depth mean speed of $6.4 \times 10^{-3} \mathrm{~m} \mathrm{~s}^{-1}$ ) is generated on the easten side (Figure 7a). Maximum vertical velocities occur along the canyon rim. This antisymmetrical structure of the vertical 
(a)

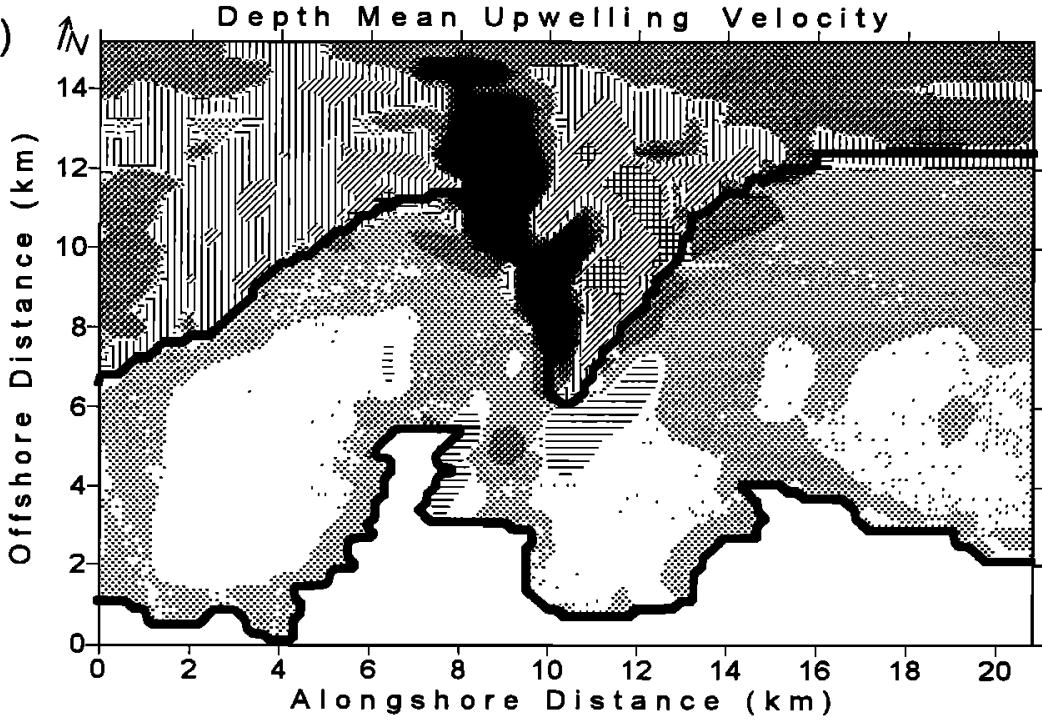

(b)

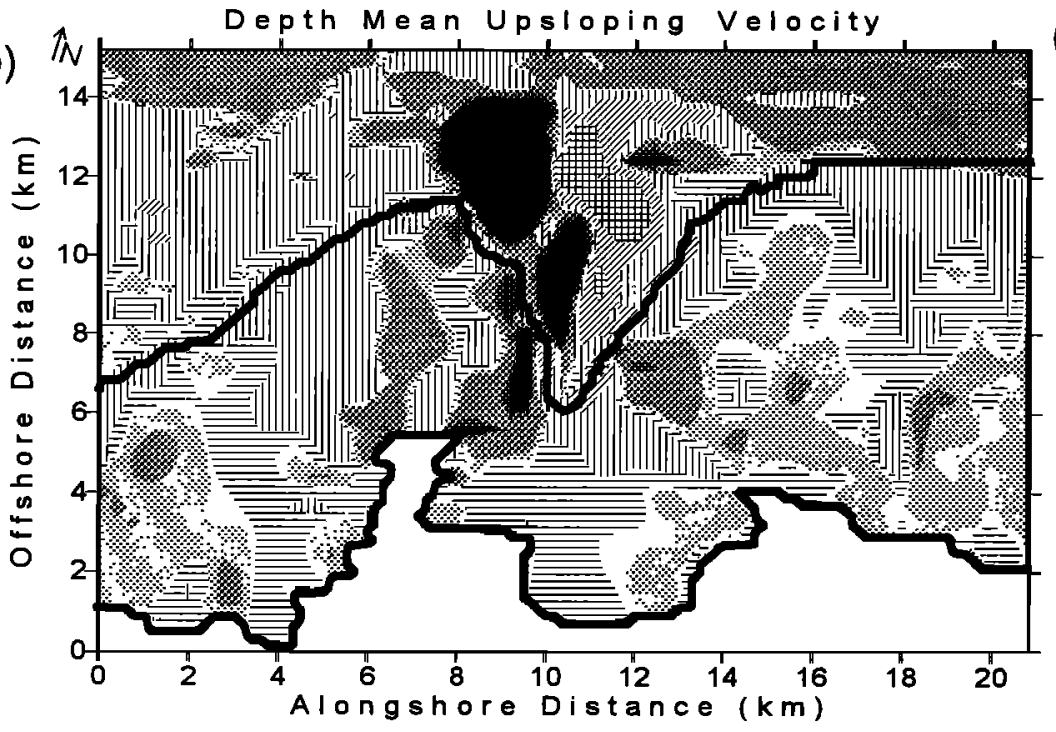

$(\mathrm{m} / \mathrm{s})$

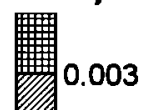

0.001

0.0001

$1 \mathrm{E}-005$

0

$-1 \mathrm{E}-005$

$-0.0001$

$-0.001$

$-0.003$

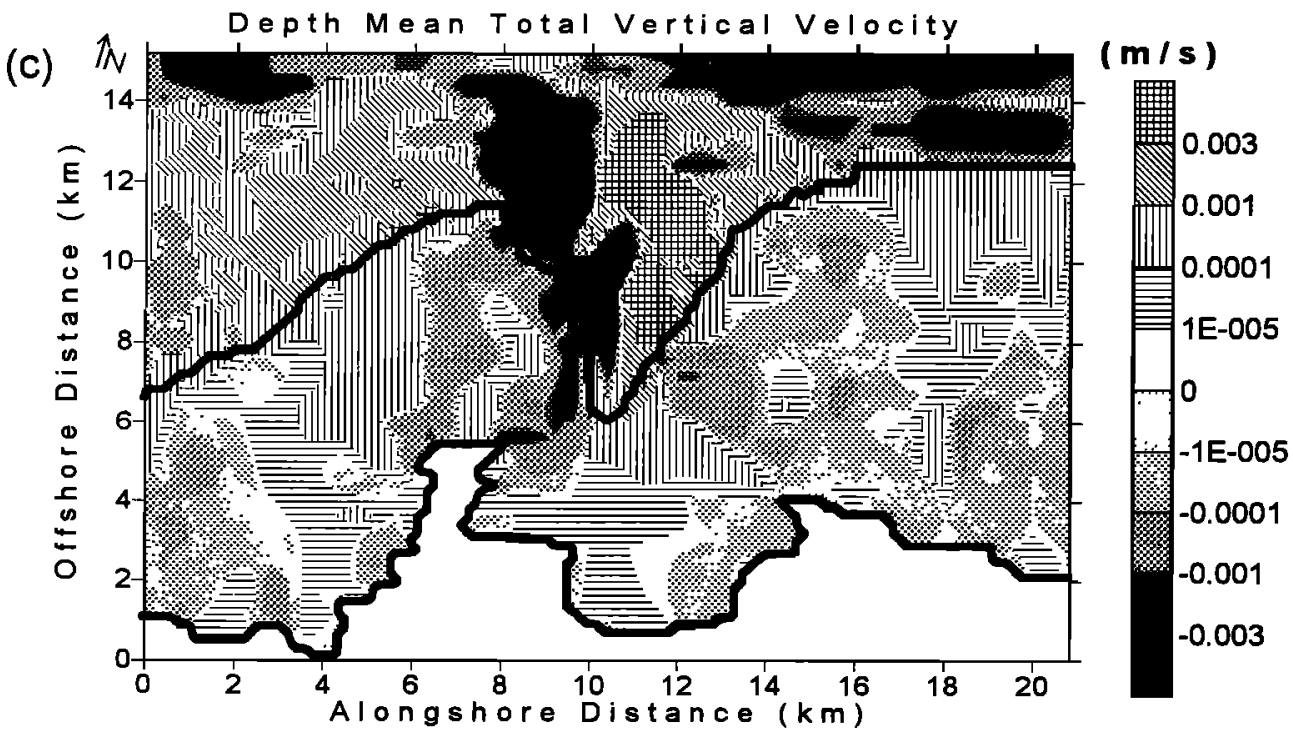

Figure 7. Depth mean vertical current velocities $\left(\mathrm{m} \mathrm{s}^{-1}\right)$ for the no-wind case. The solid line is the $150 \mathrm{~m}$ isobath, indicating the shelf edge. Positive (negative) values correspond to upward (downward) vectors. (a) Upwelling velocity. (b) Upsloping velocity. (c) Total or real vertical velocity. 
Table 1. Alongshore, Cross-Shore, and Vertical Volume Transports for the Three Model Cases

\begin{tabular}{lccc} 
& No Wind & SW Wind & NE Wind \\
\hline$U_{1}^{\text {net }}$ & 63.89 & 77.85 & 47.34 \\
$U_{1}^{+}$ & 63.89 & 77.85 & 48.47 \\
$U_{1}^{-}$ & 0.00 & 0.00 & -1.13 \\
$U_{2}^{\text {net }}$ & 47.58 & 63.20 & 27.53 \\
$U_{2}^{+}$ & 47.58 & 63.20 & 31.87 \\
$U_{2}^{-}$ & 0.00 & 0.00 & -4.34 \\
$V_{1}^{\text {net }}$ & 6.14 & 4.08 & 11.82 \\
$V_{1}^{+}$ & 28.96 & 28.73 & 32.02 \\
$V_{1}^{+}$ & -22.82 & -24.65 & -20.20 \\
$V_{2}^{\text {net }}$ & 9.05 & 7.43 & 12.47 \\
$V_{2}^{+}$ & 25.23 & 24.93 & 26.88 \\
$V_{2}^{-}$ & -16.18 & -17.50 & -14.40 \\
$V_{3}^{\text {not }}$ & -1.12 & -3.14 & 4.49 \\
$V_{3}^{+}$ & 2.70 & 3.01 & 6.64 \\
$V_{3}^{-}$ & -3.82 & -6.15 & -2.15 \\
$W^{\text {net }}$ & -9.05 & -7.43 & -12.47 \\
$W^{+}$ & 21.96 & 20.79 & 23.19 \\
$W^{+}$ & -31.01 & -28.22 & -35.66 \\
\hline
\end{tabular}

See text in section 3.3 and Figure 3. Units are $10^{3} \mathrm{~s}^{-1}, U, V, W$ are alongshore, cross-shore, and vertical volume transports, respectively. Subscripts net, + , and - denote net, positive and negative fluxes, respectively. Subscript numbers denote the plane (Figure 5) for which the transport is calculated. All transports reported in this table are counted positively when directed offshore, eastward, or upward and are counted negatively when directed onshore, westward, or downward.

flow within the canyon is also predicted by the model of Klinck [1996] for a right-bounded incident flow, showing a downwelling motion on the upstream side of the canyon, followed by an upwelling on the downstream side. In addition, near the bottom the extreme bathymetric conditions in the deep canyon area induce high downsloping (upsloping) velocities in the western (eastern) part of the canyon, which are of the same order of magnitude with Ekman vertical velocities (Figure 7b). The combined effects of downwelling (upwelling) and downsloping (upsloping) are responsible for a large vertical transport in the canyon area ( 2 or 3 orders of magnitude larger than outside the canyon) (Figure 7c). The downward flow leaving the upper $150 \mathrm{~m}$ layer in the western part of the canyon $(W)$ is $3.1 \times 10^{4} \mathrm{~m}^{3} \mathrm{~s}^{-1}$, whereas the upward flow reaching the upper $150 \mathrm{~m}$ layer in the western part $\left(W^{+}\right)$ is $2.2 \times 10^{4} \mathrm{~m}^{3} \mathrm{~s}^{-1}$, indicating a small net downward motion (Table 1). Within the canyon the vertical flow represents, on average, $11 \%$ of the horizontal flow.

Figure 8 shows current velocities in vertical sections across and along the canyon axis. On the cross-canyon section, both the horizontal and vertical velocities are maximum on the topographic slope and minimum on the central axis (Figure 8b). The along-canyon flow also exhibits a high spatial variability (Figure 8c). With the lowest values offshore, it gradually increases in intensity to reach maximum values at the canyon head. The latter appears to be a region of high exchange between the bay and the deep canyon area. Model results indicate that the canyon topography enhanced the cross-shelf transport, with an onshore upstream transport and an offshore downstream transport. The computed value of cross-shelf (onshore) transport at the western side of the canyon is $3.3 \times 10^{4} \mathrm{~m}^{3} \mathrm{~s}^{-1}$, whereas the cross-shelf (offshore) transport at the eastern side is lower $\left(2.4 \times 10^{4} \mathrm{~m}^{3} \mathrm{~s}^{-1}\right)$. On average,
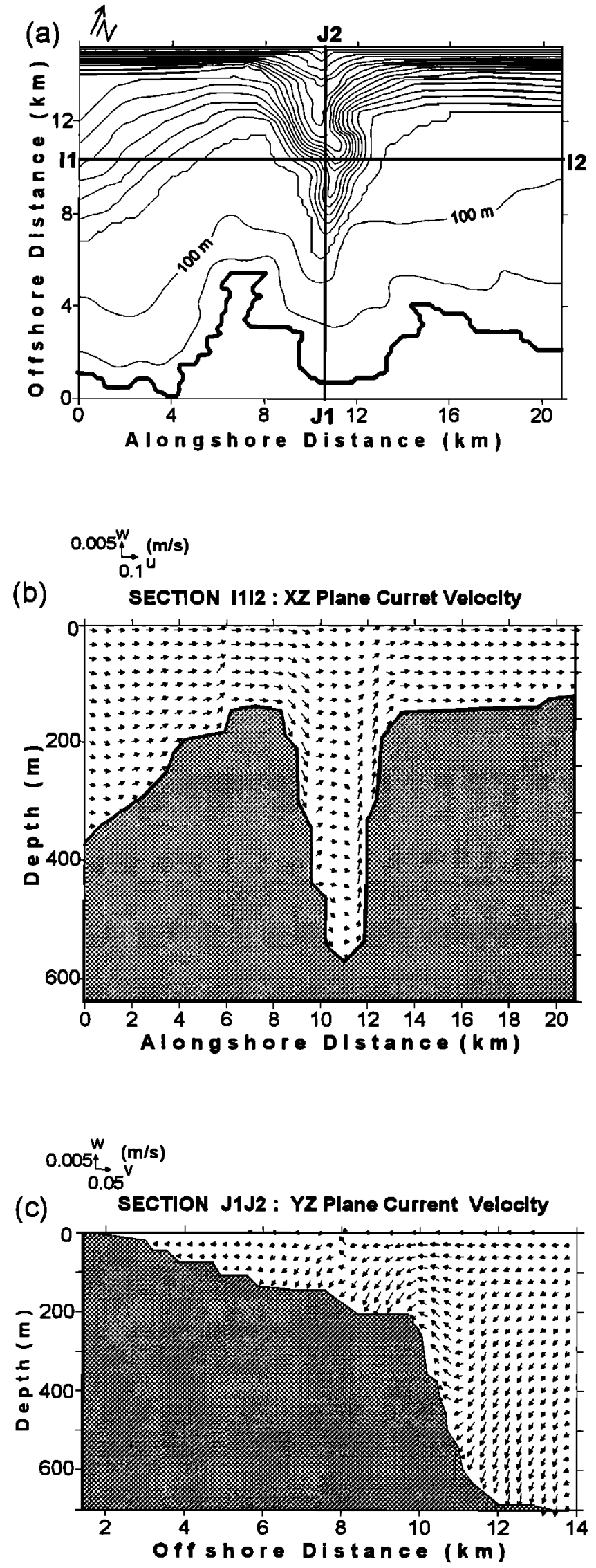

Figure 8. Currents in vertical cross sections. (a) Location of the selected sections in the computational domain. (b) Across canyon section. (c) Along canyon section. 
the ratio cross-shelf/along-shelf transport (absolute value) equals 0.36 for the shelf break around the canyon, while it remains much lower on the shelf break at the western (0.09) and eastem (0.03) shelves. The alongshore volume transport (Table 1) is much larger upstream $\left(U_{1}\right)$ than downstream of the canyon $\left(U_{2}\right)$, indicating intense cross-shore water movement within the domain. Indeed, the flux difference $\left(U_{1}-U_{2}\right)$ is compensated by a net positive (offshore) cross-shore flux in the deep canyon area $\left(V_{1}^{\text {net }}+V_{2}^{\text {net }}\right)$ where both upper and lower layer onshore transports $\left(V_{1}^{-}, V_{2}\right)$, which occur in the upstream part of the canyon, are smaller than the offshore transports $\left(V_{1}^{+}, V_{2}^{+}\right)$occurring in the downstream part. On the contrary, a small net onshore transport occurs near the bay $\left(V_{3}^{\text {net }}\right)$ with upstream negative values being higher than downstream positive values.

These transport calculations highlight the cyclonic turning of the flow in the canyon area. However, the antisymmetrical structure of vertical and horizontal flows is disturbed by the asymmetry of the canyon geometry and the presence of the bay, which induce significant differences in transports upstream or downstream of the central axis of the canyon. Hence exchange across the shelf break and vertical transport are significantly higher in the downstream than in the upstream side of the canyon, while net cross-shore transport is negative (onshore) near the Bay and positive (offshore) near the canyon mouth.

In order to address some dynamical aspects of the simulated flow pattern, an analysis of the different terms of the steady state momentum equation, based on the model results, is performed. To simplify the analysis, the depth-averaged momentum equation is considered, since the vertical shear of horizontal velocity is relatively small in the no-wind case. Bearing in mind that no-wind stress is applied and that stratification effects are not taken into account, the depth average of the steady state horizontal momentum equation reads

$$
f \mathbf{e}_{\mathbf{2}} \times \overline{\mathbf{u}}-g \nabla \zeta+\nabla \cdot(\mathbf{u u})+\tilde{\nabla}_{h} \cdot\left[K_{h} \tilde{\nabla}_{h}(\mathbf{u})\right]+\frac{1}{H} \tau_{b}=0,
$$

where $\overline{\mathbf{u}}$ is the depth-averaged horizontal velocity. Analysis results show that generally the first two terms represent the dominant part of (22) so that the simulated current velocity is very close to the geostrophic velocity $u_{g}\left(u_{B}=\left(g / f \mathbf{e}_{z} \times \zeta\right)\right.$ except for the canyon area and near the bay. The relative magnitude of the ageostrophic component of the flow may be measured by the ratio $\left|\mathbf{u}_{\mathrm{g}}-\overline{\mathbf{u}}\right| /|\overline{\mathbf{u}}|$. Upon denoting $|y|_{\text {ms }}$ the root mean square taken over the entire computational grid of the variable $y$, one gets $\left\|\mathbf{u}_{\mathrm{g}}-\overline{\mathbf{u}} \mid / \overline{\mathbf{u}}\right\|_{\mathrm{ms}}=0.11$, which means that geostrophic velocity, roughly speaking, accounts for $89 \%$ of the mean horizontal velocity. The ratio $\left|\mathbf{u}_{\mathrm{R}}-\overline{\mathbf{u}}\right| /|\overline{\mathbf{u}}|$ (Figure $9 a)$ is minimum on the shelf and the open sea while it presents high values in the nearshore area and near the canyon with a maximum of about 0.35 around the canyon rim. Within the bay the maximum $(\sim 0.25)$ is obtained in the western part where the closed anticyclonic circulation takes place. The horizontal diffusion term and the bottom stress are too small to explain the ageostrophic component of the flow around the canyon. The horizontal Ekman number $E_{k}$ measuring the magnitude of the horizontal diffusion term relative to the Coriolis force is defined by

$$
E_{k}=\frac{K_{h}}{f L^{2}} \frac{\left|\nabla \cdot\left(K_{h} \nabla \mathbf{u}\right)\right|}{\left|f \mathrm{e}_{\mathbf{z}} \times \overline{\mathbf{u}}\right|},
$$

where $L$ denotes the horizontal length scale. One has $\left|E_{k}\right|_{\text {ms }}$ $=0.01$, which means that, for the basin scale motions, horizontal diffusion is negligible. $E_{k}$ reaches a maximum value of 0.06 within the bay and thus horizontal diffusion is still too small there as compared with the Coriolis term. For the bottom stress term, one has $\left\|\tau_{b} / H|/| \mathrm{e}_{\mathbf{z}} \times \overline{\mathbf{u}}\right\|_{\mathrm{ms}}=0.018$. This ratio presents minimum values on the shelf and in deep regions away from the canyon $(\sim 0.01)$, relatively high values near the shelf break $(\sim 0.03)$ and maximum values within the western part of the bay $(-0.09)$, where the bottom stress decelerates the flow and creates a small but significant ageostrophic transport. Advection appears to be the most important term responsible for the difference from geostrophic balance. This may be verified by evaluating the Rossby number $R_{o}$ :

$$
R_{o}=\frac{U}{f L}=\frac{|\nabla \cdot(\overline{\mathbf{u}})|}{\left|f \mathbf{e}_{\mathbf{z}} \times \overline{\mathbf{u}}\right|}
$$

where $U$ denotes the horizontal velocity scale. Indeed, one has $\left|R_{o}\right|_{\text {rms }}=0.13$, with maximum values around the canyon rim $\left(R_{o} \sim 0.75\right)$ and with relatively high values around the western edge of the bay $\left(R_{o} \sim 0.3\right)$, so that $R_{0}$ horizontal distribution pattern (Figure $9 \mathrm{~b}$ ) roughly fits that of the ratio $\left|\mathbf{u}_{\mathrm{g}}-\overline{\mathbf{u}}\right| /|\overline{\mathbf{u}}|$. Thus nonlinear dynamics, far from being negligible, is responsible for a significant ageostrophic transport that is more visible around the canyon rim and in the westem part of the bay.

\subsection{Simulations With Wind Forcing}

Model results for the SW wind event case show that the mean horizontal flow is strengthened by the wind, especially in the nearshore area where the wind forcing affects the whole water column (Figure 10a). The mean flow pattern is rather similar to the no-wind case, but the anticyclonic gyre in the western part of the bay as well as the cyclonic circulation in the eastem part of the bay are clearly reinforced. An offshore flow of high intensity (about 10 times larger than the no-wind case) is obtained at the eastern edge of the bay. Another effect of SW winds is to reduce cyclonic vorticity within the canyon. The result is that cross-shelf exchange in the canyon region is enhanced. The mean ratio of cross-shelf/along-shelf transport is increased about $15 \%$ with respect to the no-wind simulation. In the bay, the vertical structure of the flow presents a high variability. Surface currents (Figure 10b), induced by the wind stress, are more intense and generally oriented northeastward, while bottom currents (Figure 10c) are weaker and oriented southwestward. As a result, a marked coastal downwelling (upwelling) occurs in the eastern (westem) part of the bay (Figure 11). Within the deep canyon area, modifications of the vertical flow pattern were rather limited, as compared with the no-wind simulation. However, model results indicate a small but significant decrease of vertical velocities within the canyon. The downward flow leaving the upper $150 \mathrm{~m}$ layer in the eastern part of the canyon $(W)$ is reduced about $9 \%$, whereas the upward flow reaching this layer in the westem part $\left(W^{\dagger}\right)$ is reduced about 7\%. The alongshore transports $U_{1}, U_{2}$ are increased about $19 \%$ and $27 \%$, respectively, while the total net cross-shore transport in the deep canyon area $\left(V_{1}^{\text {net }}+V_{2}^{\text {net }}\right)$ is decreased about $29 \%$ indicating again that cyclonic vorticity within the canyon is reduced. Both offshore and onshore fluxes in front of the Calvi Bay are increased and the net (onshore) transport $\left(V_{3}^{\text {net }}\right)$ is about 3 times larger than 

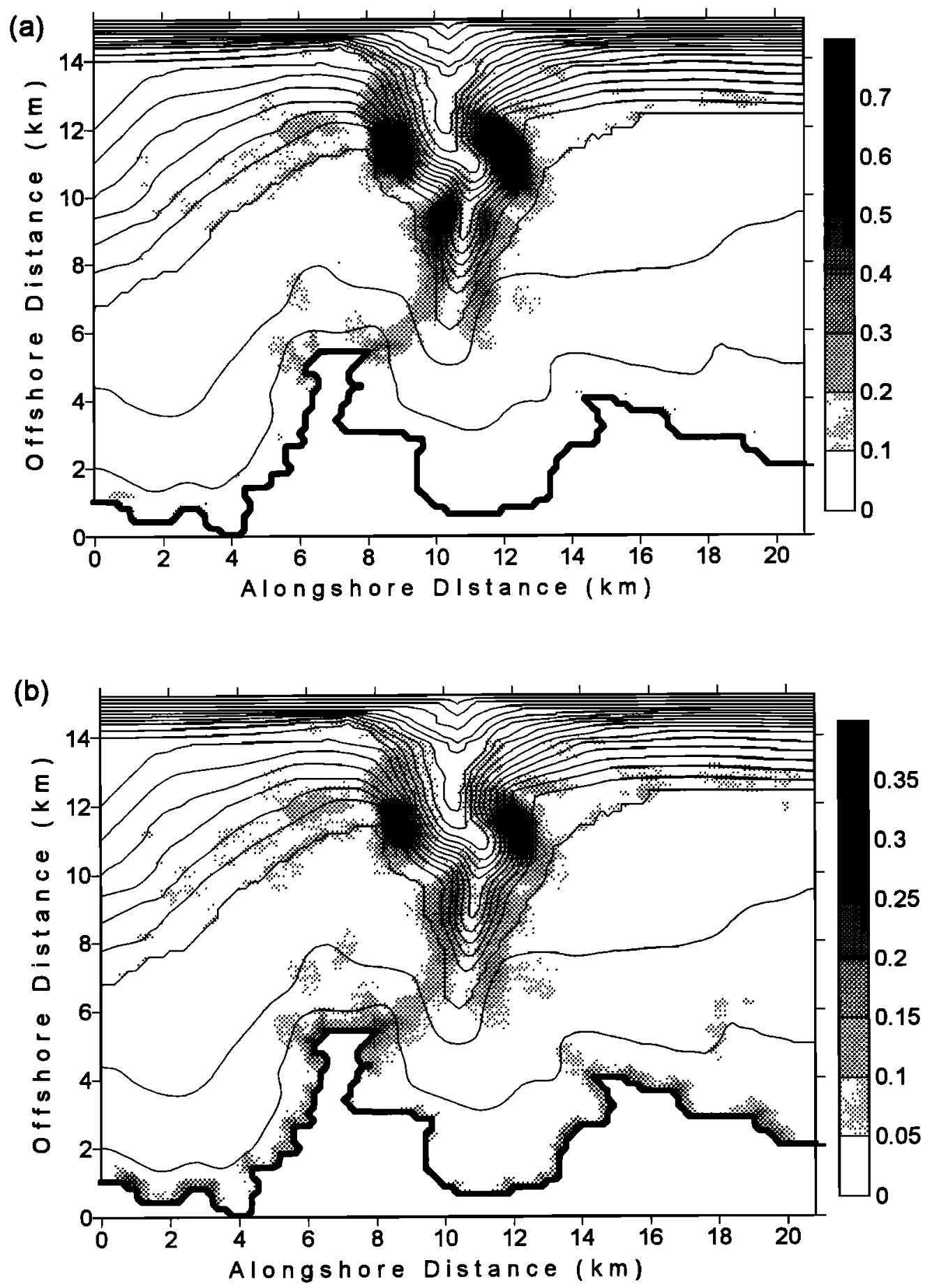

Figure 9. Analysis results for the depth-averaged steady state momentum equation. Horizontal distribution of (a) the relative difference from the geostrophic flow $\left|\mathbf{u}_{\mathrm{g}}-\overline{\mathbf{u}}\right| / \overline{\mathbf{u}} \mid$ and (b) the Rossby number $R_{o}$. Isobaths with a contour interval of $50 \mathrm{~m}$ are also depicted.

in the no-wind case, indicating much more efficient exchange between the bay and the canyon area in this case.

The N-NE wind induces a reversal of the flow direction in the nearshore area. Within the bay a strong anticyclonic mean circulation is simulated (Figure 12a) with an offshore flow at the head of the canyon. On the other hand, currents of high intensity (an order of magnitude larger with respect to the nowind case) enter into the eastem part of the bay. The circulation in the westem part of the bay is now reversed and weaker. The flow is no longer uniform on the shelf domain and the ageostrophic component of the current is enhanced. The wind forcing induces a further increase of negative relative vorticity upstream and downstream of the canyon. As a result, the anticyclonic circulation patterns on the eastem and western shelves are reinforced. On the contrary, the wind event induces an increase of positive relative vorticity within the canyon, which results in a further enhancement of the cyclonic circulation. Thus while the exchanges between the bay and the canyon head are stimulated, the overall effect of the N-NE wind on the cross-shelf exchanges is to decrease 

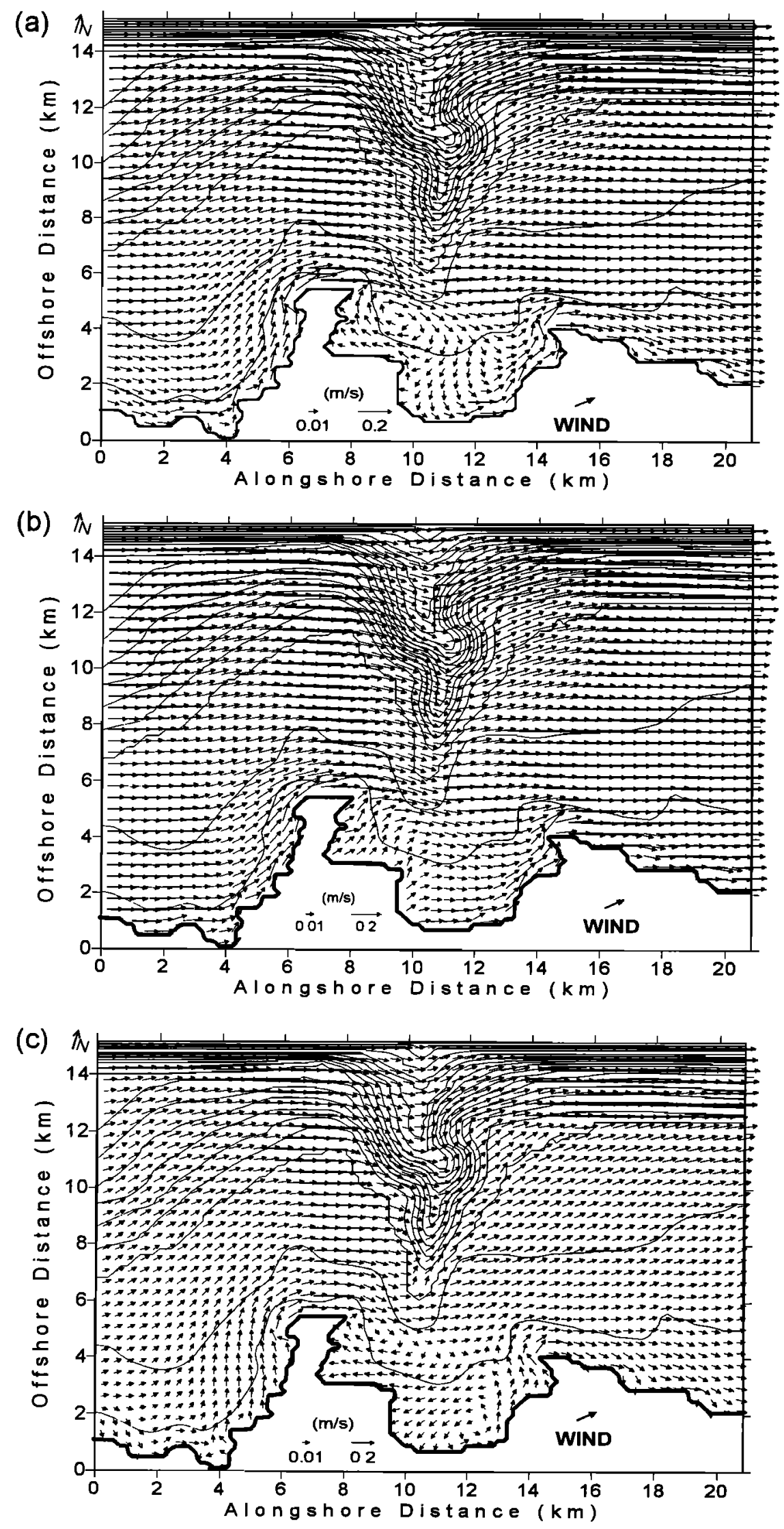

Figure 10. Horizontal current velocities $\left(\mathrm{m} \mathrm{s}^{-1}\right)$ for the $\mathrm{SW}$ wind case. (a) Depth mean velocity. (b) Near surface velocity. (c) Near bottom velocity. 


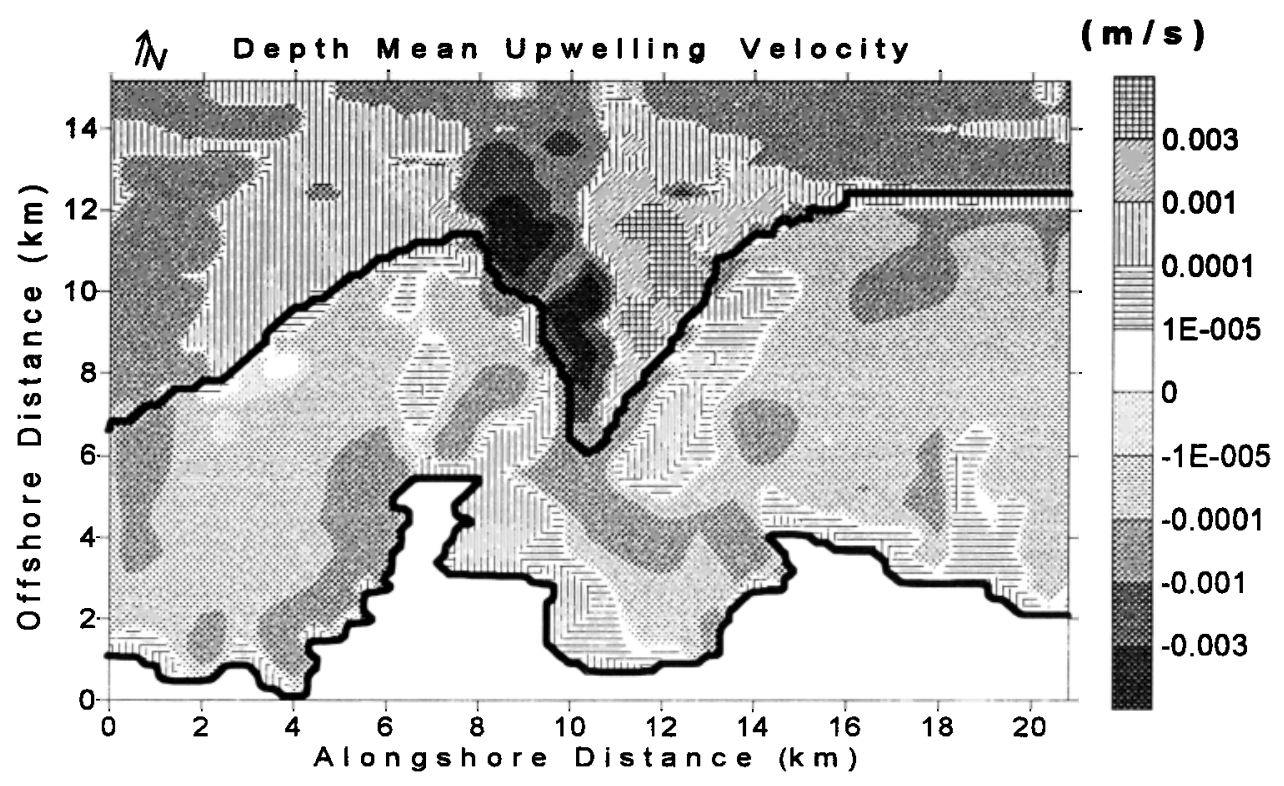

Figure 11. Depth mean upwelling velocities $\left(\mathrm{m} \mathrm{s}^{-1}\right)$ for the $\mathrm{SW}$ wind case.

their intensity. The mean ratio of cross-shelf/along-shelf transport in the canyon area is decreased about $17 \%$ with respect to the no-wind simulation.

Wind-driven surface currents are now oriented southwestward (Figure 12b), while bottom currents are oriented northeastward (Figure 12c), leading to a strong coastal upwelling in the eastern part of the bay (Figure 13). The vertical flow within the canyon is relatively enhanced compared with the no-wind case. The downward flow leaving the upper $150 \mathrm{~m}$ layer in the eastern part of the canyon $(W)$ is increased about $15 \%$, whereas the upward flow reaching this layer in the western part $\left(W^{+}\right)$is increased about $10 \%$ (Table 1). The alongshore net transports $U_{1}^{\text {net }}, U_{2}^{\text {net }}$ are decreased (with respect to the no-wind case) about $26 \%$ and $42 \%$, respectively, due to the wind-driven flow reversal near the coast. On the other hand, the total net cross-shore transport in the deep canyon area $\left(V_{1}^{\text {net }}+V_{2}^{\text {net }}\right)$ is increased about $60 \%$ as a result of enhancement of cyclonic vorticity in the canyon area. In front of the Calvi Bay the net cross-shore transport $\left(V_{3}^{\text {net }}\right)$ is now directed offshore and is about 4 times larger than in the nowind case. This outflow is compensated by an intense inflow offshore of the eastern edge of the bay.

Model results for the wind-driven cases indicate that, within the canyon, vertical velocities increase with the intensity of cyclonic vorticity that depends on the wind direction. For both wind cases the simulated surface circulation pattern within the Calvi Bay and downstream of the canyon head is in agreement with field observations (see Figures $2 \mathrm{c}$ and $2 \mathrm{~d}$ ).

\subsection{Implications of the Canyon Circulation}

The model results suggest that the hydrodynamics of the canyon in relation with the wind conditions should have an effect on biological activity. As it was mentioned in the previous section, both wind cases are associated with much higher exchange (with respect to the no-wind case) between the bay and the offshore area. A dramatic increase of nitrate concentration of the surface waters of the Calvi Bay is often observed in early spring during NE wind events (Figure 14)
[Goffart et al., 1995]. A phytoplankton bloom then occurs with a chlorophyll concentration maximum generally observed 1 or 2 days after the passage of the wind event. On the other hand, observations do not show such efficient nitrate enrichment of the bay during SW wind events. Typical nitrate vertical profiles during that period show that nitrate concentration is relatively high in deep layers (>50 m depth) while it rapidly decreases to reach very low levels near the surface as a consequence of intense consumption by the phytoplankton in the euphotic layer. Bearing in mind that depth within the bay varies from 10 to $50 \mathrm{~m}$ nitrate concentrations within the entire water column remain low. One then may argue that the rapid increase of nitrate within the bay involves the presence of deep water, an indicator of the water masses renewal. Model results for the NE wind case (Figure 12c) indicate the presence of a bottom current of high intensity (an order of magnitude larger than in the no-wind case) entering into the eastern part of the bay. As a result, an onshore transport of deeper water, richer in nitrate, takes place. Intense upwelling $\left(v_{3} \sim 5 \times 10^{-4} \mathrm{~m} \mathrm{~s}^{-1}\right)$ and turbulent mixing $\left(\tilde{v} \sim 10^{-2} \mathrm{~m}^{2} \mathrm{~s}^{-1}\right)$ then induce a vertical nitrate transport into the surface layer while surface currents are responsible for the nitrate dispersion within the entire bay. Furthermore, two suggestions may be made to explain the larger nitrate increase during NE wind events as compared with the SW wind case. The NE wind case bottom circulation pattern (Figure 12c) shows a large, closed anticyclonic circulation within the bay, indicating that the residence time of transported nitrate from the open sea is larger there, leading to a further nitrate increase. Moreover, one may expect higher nitrate concentrations downstream of the canyon due to the intense upwelling in the western part of the canyon. Unlike the SW wind case, model results show that in the NE wind case bottom circulation presents an anticyclonic turning downstream of the canyon so that a part of the bottom flow enters into the bay and thus induces a more intense nitrate transport there.

Field observations of biological/chemical variables near the canyon highlight the impact of the 3-D flow on the plankton ecosystem. Figure 15 shows, for example, the horizontal 
(a)

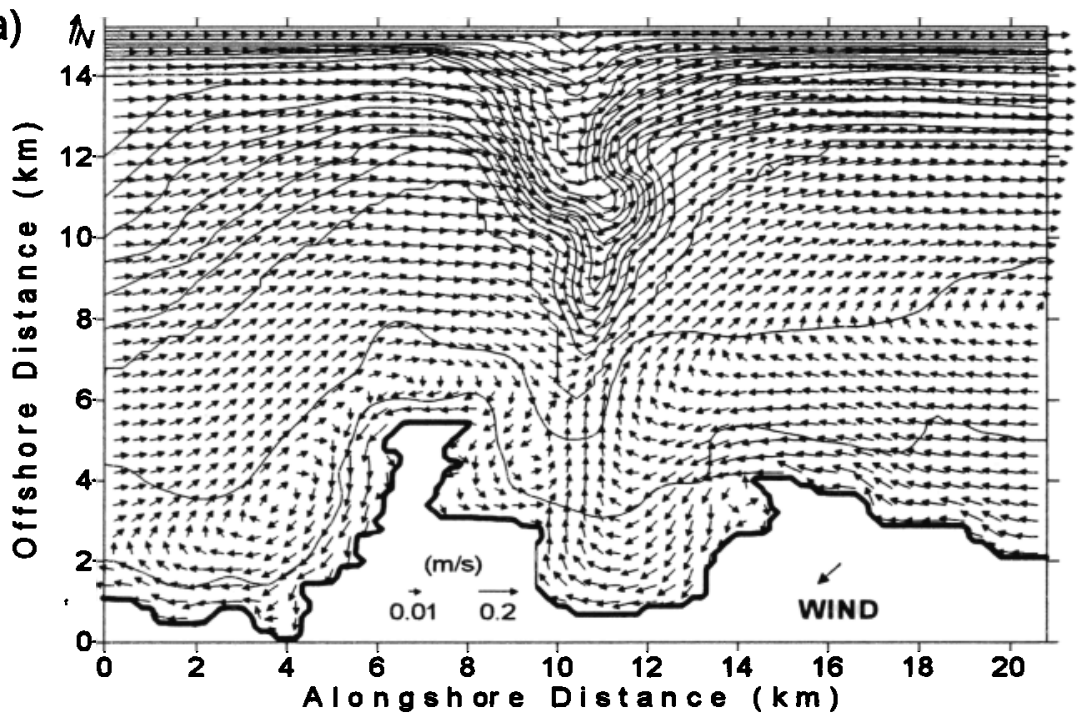

(b)
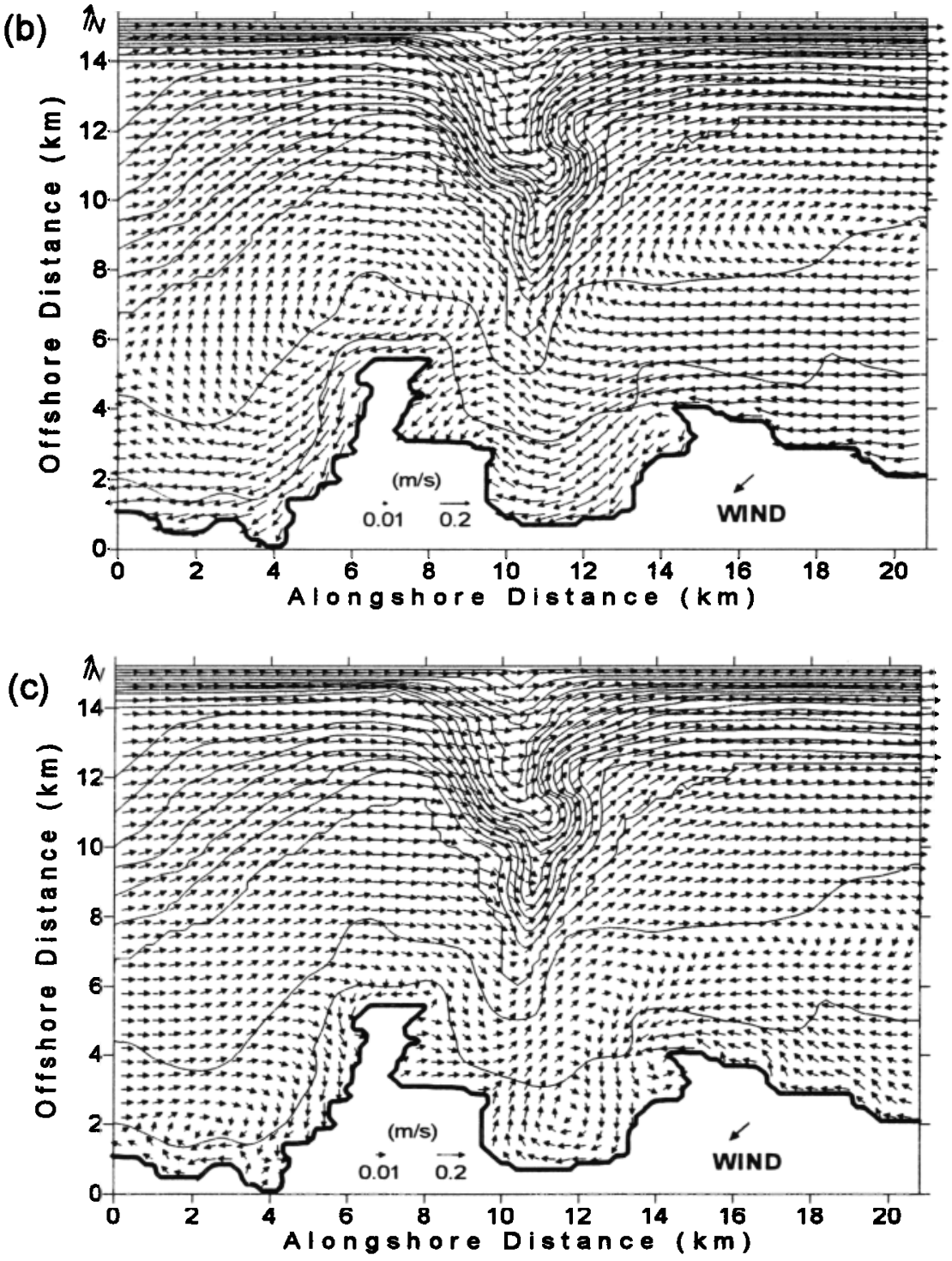

Figure 12. Horizontal current velocities $\left(\mathrm{m} \mathrm{s}^{-1}\right)$ for the N-NE wind case. (a) Depth mean velocity. (b) Near surface velocity. (c) Near bottom velocity. 


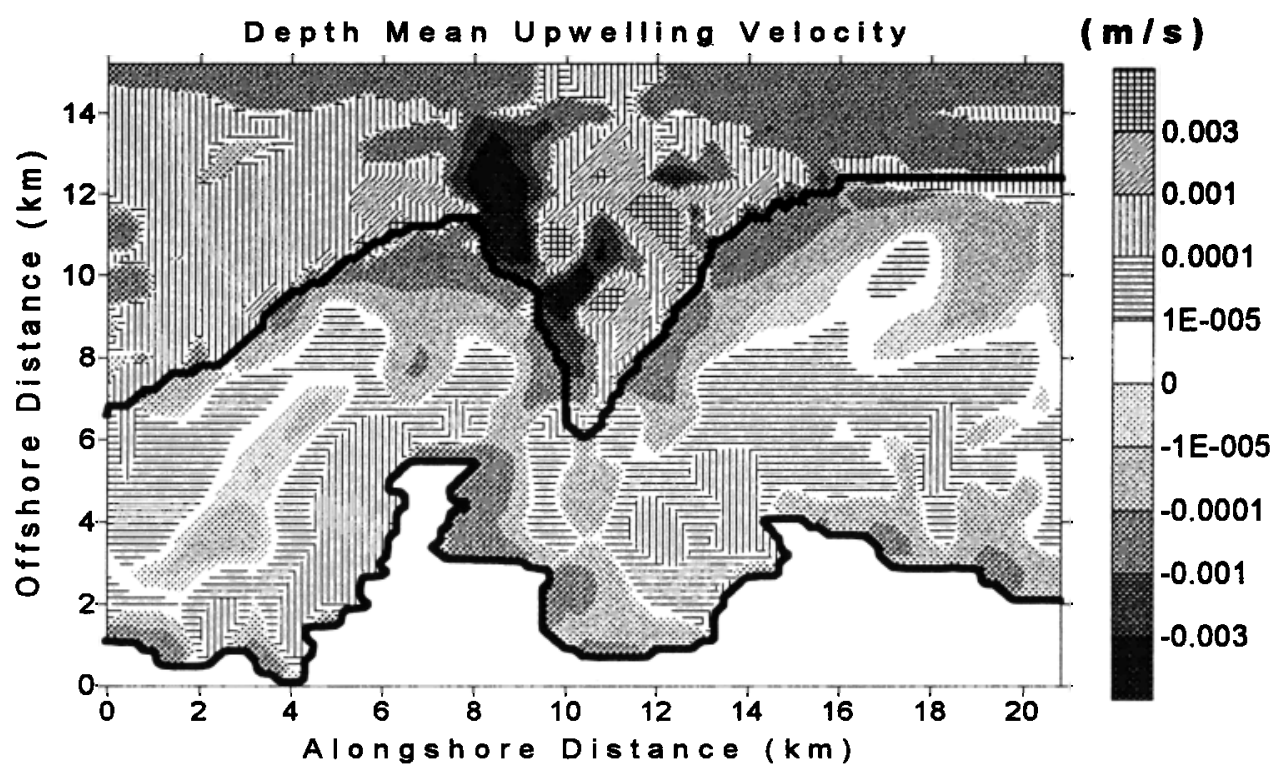

Figure 13. Depth mean upwelling velocities $\left(\mathrm{m} \mathrm{s}^{-1}\right)$ for the N-NE wind case.

distribution at $50 \mathrm{~m}$ depth of nitrate and chlorophyll $a$ concentrations (A. Goffart, unpublished data, 1997) measured in the region of interest at the end of the winter (February 28, 1997). This period is prior to the onset of the phytoplankton bloom, when relatively low light conditions are limiting the primary production at high depths. Before the sampling day a strong SW wind event was reported. A high horizontal variation of nitrate concentration is observed, with maximum values in the eastern side and downstream of the canyon. This could be explained by the fact that upwelling motion in the eastern part of the canyon transported the deep nitrate upwards at the canyon edge, and then the surface current, under the influence of SW winds, transported the upwelled nitrate eastward. The distribution of chlorophyll $a$ presents significantly higher concentrations upstream and over the canyon than downstream of the canyon. This could be also associated with the downwelling-upwelling motion in the canyon area, which is responsible for a downward transport of surface water (with relatively high phytoplankton concentration) at the western edge of the canyon and of an upward transport of deep water (characterized by low phytoplankton concentration) at the eastern edge of the canyon.

Another important feature derived from the model results is that the canyon acts as a sediment trap, in agreement with observational studies in other NW Mediterranean canyons [Granata et al., 1999; Monaco et al., 1999]. On one hand, the mean downward transport is significantly higher than the upward transport within the canyon, and on the other hand,

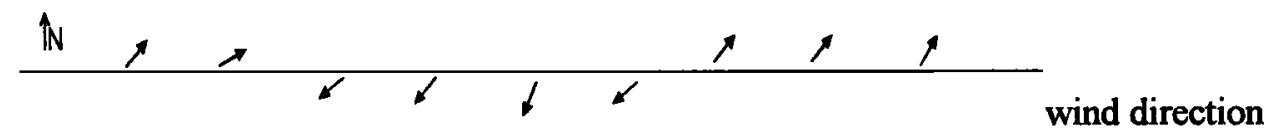

- Nitrate $-x-$ Wind speed

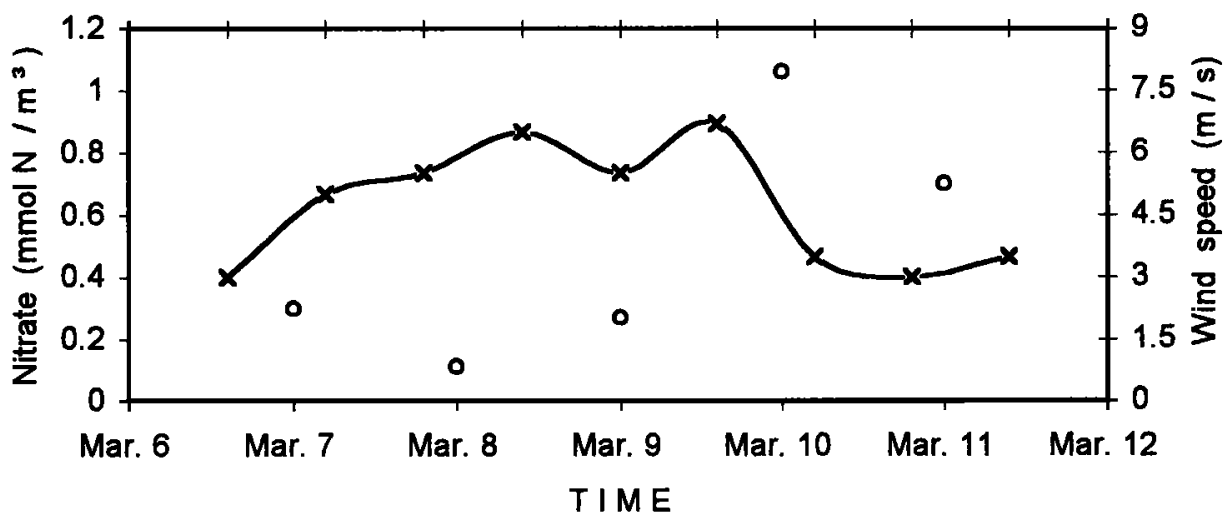

Figure 14. Time variations of measured surface nitrate concentration (circles) and wind intensity (crosses) within the western part of the Calvi Bay (March 6 to March 12, 1988). Wind direction is also depicted. 

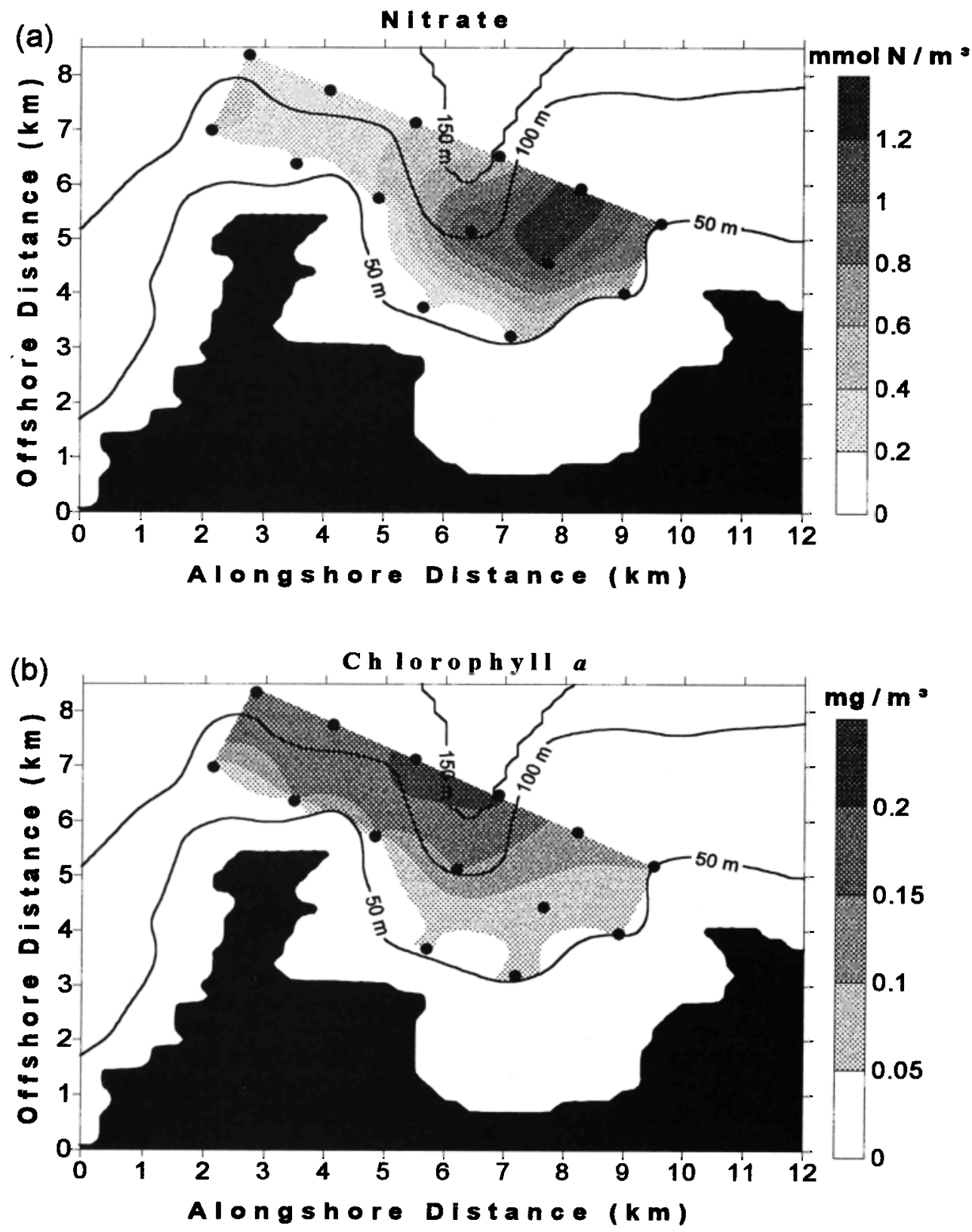

Figure 15. Horizontal distribution at $50 \mathrm{~m}$ depth of (a) nitrate concentration $\left(\mathrm{mmol} \mathrm{N} / \mathrm{m}^{3}\right)$ and (b) chlorophyll $a$ concentration ( $\mathrm{mg} \mathrm{m}^{-3}$ ). Measurements were made February 28, 1997.

the low velocity field over the canyon suggests that the residence time of suspended material is larger there, allowing sedimentation of particles to the bottom.

\section{Concluding Remarks}

The use of the GHER 3-D hydrodynamic model made possible the evaluation of the water mass exchanges between a narrow small-scale canyon and the shelf and nearshore domains. High horizontal resolution allowed the simulation of nonlinear, small-scale flow structures under the influence of steep and irregular topography. The model results are in agreement with field observations and show that the circulation within the Calvi Bay is in close relation with flow modifications in the canyon region. The mean flow is deflected by the canyon to form an anticyclonic circulation in the western part of the bay. Within the canyon a cyclonic circulation occurs, generating an offshore flow downstream of the canyon. Cross-shelf transport is an order of magnitude higher in the canyon region than over the remainder of the shelf break. Furthermore, the model results demonstrated that the canyon topography is responsible for a strong downwelling-upwelling motion dominating the vertical transport of material and thus regulating the biological interactions in the area. The effect of the wind forcing on the flow pattern appears to induce strong anticyclonic (NE wind) or cyclonic (SW wind) circulation within the bay as well as strong coastal upwellingdownwelling motion. Cross-shore transports in front of the bay become 3-4 times larger than in the no-wind case. Vertical velocity within the canyon is an increasing function of cyclonic vorticity which is enhanced (reduced) by the N-NE (SW) wind event. SW winds significantly increase cross-shelf 
exchanges, while N-NE winds cause, on average, an opposite effect. However, the exchanges are increased at the canyon head, indicating that in that case the canyon plays the role of a transition zone for an intense offshore transport of organic particles and pollutants produced within the bay.

Furthermore, simulations for the baroclinic case should be performed to investigate the dynamics in a strongly stratified period, for example, prior to a secondary phytoplankton bloom. Additional runs need also to be considered to assess the effects of the seasonal variability of the West Corsica Current intensity that determines the incident alongshore flow characteristics. Moreover, instabilities of the LiguroProvençal front may induce short-timescale variability of the slope current and shelf-slope exchanges in the coastal area of Calvi. A larger scale, high-resolution model should be developed to investigate the interaction of such complex dynamic instabilities with the canyon/shelf system.

Acknowledgments. The authors would like to thank the staff of the Station de Recherches Sous-marines et Océanographiques (Calvi, Corsica), and the crew of the R.V. Recteur Dubuisson for their valuable contribution. This work was achieved in the frame of projects supported by the Communauté Française de Belgique (A.R.C. 97/02.112) and the Fonds National de la Recherche Scientifique (FRFC 2.4570.97 and FRFC 2.4609.99). J.-H. Hecq is a F.N.R.S. Chercheur Qualifié.

\section{References}

Allen, S.E., Topographically generated, subinertial flows within a finite length canyon, J. Phys. Oceanogr., 26, 1608-1632, 1996.

Alvarez, A., J. Tintoré, and A. Sabatés, Flow modification and shelfslope exchange induced by a submarine canyon off the northeast Spanish coast. J. Geophys. Res., 101, 12,043-12,055, 1996.

Ardhuin, F., J.M. Pinot, and J. Tintoré, Numerical study of the circulation in a steep canyon off the Catalan coast (western Mediterranean), J. Geophys. Res., 104, 11,115-11,135, 1999.

Astraldi, M., and G.P. Gasparini, The seasonal characteristics of the circulation in the north Mediterranean basin and their relationship with the atmospheric-climatic conditions, J. Geophys. Res., 97, 9531-9540, 1992.

Beckers, J.M., Application of the GHER 3D general circulation model to the Western Mediterranean, J. Mar. Syst., 1, 315-332, 1991.

Blumberg, A.F., and G.L. Mellor, A description of a threedimensional coastal ocean circulation model, in ThreeDimensional Coastal Ocean Models, Coastal Estuarine Sci., vol. 4, edited by N.S. Heaps, pp. 1-16, AGU, Washington, D.C., 1987.

Crank, J., and P. Nicolson, A practical method for numerical evolution of solution of differential equations of the heat conduction type, Math. Proc. Cambridge Philos. Soc., 50, 50-67, 1947.

Deleersnijder, E., Upwelling and upsloping in three-dimensional marine models, Appl. Malh. Modell., 13, 462-467, 1989.

Deleersnijder, E., and J.M. Beckers, On the use of the $\sigma$ coordinate system in regions of large bathymetric variation, J. Mar. Syst., 3, 381-390, 1992.

Djenidi, S., Observations au large de Calvi en régime d'été, Bull. Soc. R. Sci. Liège, 54, 287-300, 1985.

Djenidi, S., J.C.J. Nihoul, F. Clément, and D. Salas de Leon, The Modem contribution to Medalpex, Ann. Geophys., 5, 3-12, 1987.

Durrieu de Madron, X., Hydrology and nepheloid structure in the Gran-Rhône canyon, Cont. Shelf Res., 14, 457-477, 1994.

Freeland, H.J., and K.L. Denman, A topographically induced upwelling center off southern Vancouver Island, J. Mar. Res., 40, 1069-1093, 1982.

Freeman, N.G., A.M. Hale, and M.B. Danard, A modified sigma equations' approach to the numerical modeling of Great Lakes hydrodynamics conditions, J. Geophys. Res., 77, 1050-1060, 1972.

Geyer, W.R., and R. Signell, Measurements of tidal flow around a headland with a shipboard acoustic Doppler current profiler, $J$. Geophys. Res., 95, 3189-3197, 1990.
Goffart, A., J.H. Hecq, and L. Prieur, Control of the phytoplankton of the Ligurian basin by the Liguro-Provençal front (Corsican sector), Oceanol. Acta, 18, 329-342, 1995.

Granata, T.C., B. Vidondo, C.M. Duarte, M.P. Satta, and M. Garcia, Hydrodynamics and particle transport associated with a submarine canyon off Blanes (Spain, NW Mediterranean Sea), Cont. Shelf Res., 19, 1249-1263, 1999.

Hickey, B.M., The response of a steep-sided, narrow canyon to timevariable wind forcing, J. Phys. Oceanogr., 27, 697-726, 1997.

Hickey, B.M., E. Baker, and N. Kachel, Suspended particle movement in and around Quinault Submarine Canyon, Mar. Geol., 71, 35-83, 1986.

Hunkins, K., Mean and tidal currents in Baltimore Canyon, J. Geophys. Res., 93, 6917-6929, 1988.

James, I.D., Advection schemes for shelf sea models, J. Mar. Syst., 8, 237-254, 1996.

Klinck, J.M., The influence of a narrow transverse canyon on initially geostrophic flow, J. Geophys. Res., 93, 509-515, 1988.

Klinck, J.M., Geostrophic adjustment over submarine canyons, $J$. Geophys. Res., 94, 6133-6144, 1989.

Klinck, J.M., Circulation near submarine canyons: A modeling study. J. Geophys. Res., 101, 1211-1223, 1996.

La Violette, P.E., J. Tintoré, and J. Font, The surface circulation of the Balearic Sea. J. Geophys. Res., 95, 1559-1568, 1990

Masó, M., and J. Tintoré, Variability of the shelf water off the northeast Spanish coast, J. Mar. Syst., 1, 441-450, 1991.

Millot, C., Mesoscale and seasonal variabilities of the circulation in the Western Mediterranean, Dyn. Atmos. Oceans, 15, 179-214, 1991.

Monaco, A., X. Durrieu de Madron, O. Rodacovitch, S. Huessner, and J. Carbone, Origin and variability of downward biogeochemical fluxes on the Rhône continental margin (NW Mediterranean), Deep Sea Res., 46, 1483-1511, 1999.

Nihoul, J.C.J., A three-dimensional general marine circulation model in a remote sensing perspective, Ann. Geophys., 2, 433-442, 1984.

Nihoul, J.C.J., and S. Djenidi, Perspective in three-dimensional modeling of the marine system, in Three-Dimensional Models of Marine and Estuarine Dynamics, edited by J.C.J. Nihoul and B. Jamart, pp. 1-34, Elsevier Sci., New York, 1987.

Nihoul, J.C.J., E. Deleersnijder, and S. Djenidi, Modelling the general circulation of shelf seas by 3D $k$ - $\varepsilon$ models, Earth Sci. Rev., 26, 163-189, 1989.

Noble, M., and B. Butman, The structure of subtidal currents within and around Lydonia Canyon: Evidence for enhanced cross-shelf fluctuations over the mouth of the canyon, J. Geophys. Res., 94, 8091-8110, 1989.

Norro, A., Etude pluridisciplinaire d'un milieu côtier: Approches experimentale et de modélisation de la baie de Calvi (Corse), Ph.D. thesis, Univ. Liège, Liège, Belgium, 1995.

Peyret, R., and T.D. Taylor, Computational Methods for Fluid Flows, 388 pp, Springler-Verlag, New York, 1983.

Robinson, I.S., Tidal vorticity and residual circulation, Deep Sea Res., 28, 195-212, 1981.

Robinson, I.S., Tidally induced residual flows, in Physical Oceanography of Coastal and Shelf Seas, edited by B. Johns, pp. 321-356, Elsevier Sci., New York, 1983.

Roed, L.P., and C.K. Cooper, A study of various open boundary conditions for wind-forced barotropic numerical ocean models, in Three-dimensional Models of Marine and Estuarine Dynamics, edited by J.C.J. Nihoul and B. Jamart, pp. 305-336, Elsevier Sci., New York, 1987.

Rojas, P., et al., On the structure of the mean flow in the Blanes canyon area (NW Mediterranean) during summer, Oceanol. Acta, 18, 443-458, 1995.

S. Djenidi, A. Goffart, J.H. Hecq, and N. Skliris, Ecohydrodynamics, Geohydrodynamics and Environment Research, University of Liège, Sart Tilman B5, B4000, Liège, Belgium. (n.skliris@wanadoo.be)

(Received July 10, 2000; revised May 2, 2001; accepted May 10, 2001.) 